NASA/TM—2010-216240

\title{
Aeroelastic Computations of a Compressor Stage Using the Harmonic Balance Method
}

T.S.R. Reddy

University of Toledo, Toledo, Ohio

Milind A. Bakhle

Glenn Research Center, Cleveland, Ohio 


\section{NASA STI Program . . . in Profile}

Since its founding, NASA has been dedicated to the advancement of aeronautics and space science. The NASA Scientific and Technical Information (STI) program plays a key part in helping NASA maintain this important role.

The NASA STI Program operates under the auspices of the Agency Chief Information Officer. It collects, organizes, provides for archiving, and disseminates NASA's STI. The NASA STI program provides access to the NASA Aeronautics and Space Database and its public interface, the NASA Technical Reports Server, thus providing one of the largest collections of aeronautical and space science STI in the world. Results are published in both non-NASA channels and by NASA in the NASA STI Report Series, which includes the following report types:

- TECHNICAL PUBLICATION. Reports of completed research or a major significant phase of research that present the results of NASA programs and include extensive data or theoretical analysis. Includes compilations of significant scientific and technical data and information deemed to be of continuing reference value. NASA counterpart of peer-reviewed formal professional papers but has less stringent limitations on manuscript length and extent of graphic presentations.

- TECHNICAL MEMORANDUM. Scientific and technical findings that are preliminary or of specialized interest, e.g., quick release reports, working papers, and bibliographies that contain minimal annotation. Does not contain extensive analysis.

- CONTRACTOR REPORT. Scientific and technical findings by NASA-sponsored contractors and grantees.
- CONFERENCE PUBLICATION. Collected papers from scientific and technical conferences, symposia, seminars, or other meetings sponsored or cosponsored by NASA.

- SPECIAL PUBLICATION. Scientific, technical, or historical information from NASA programs, projects, and missions, often concerned with subjects having substantial public interest.

- TECHNICAL TRANSLATION. Englishlanguage translations of foreign scientific and technical material pertinent to NASA's mission.

Specialized services also include creating custom thesauri, building customized databases, organizing and publishing research results.

For more information about the NASA STI program, see the following:

- Access the NASA STI program home page at http://www.sti.nasa.gov

- E-mail your question via the Internet to help@ sti.nasa.gov

- Fax your question to the NASA STI Help Desk at 443-757-5803

- Telephone the NASA STI Help Desk at 443-757-5802

- Write to: NASA Center for AeroSpace Information (CASI) 7115 Standard Drive Hanover, MD 21076-1320 
NASA/TM-2010-216240

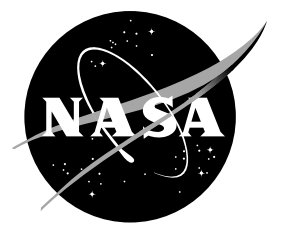

\section{Aeroelastic Computations of a Compressor Stage Using the Harmonic Balance Method}

T.S.R. Reddy

University of Toledo, Toledo, Ohio

Milind A. Bakhle

Glenn Research Center, Cleveland, Ohio

Prepared for the

45th Joint Propulsion Conference and Exhibit

cosponsored by the AIAA, ASME, SAE, and ASEE

Denver, Colorado, August 2-5, 2009

National Aeronautics and

Space Administration

Glenn Research Center

Cleveland, Ohio 44135 


\section{Acknowledgments}

Support of this work from the NASA Fundamental Aeronautics Program is gratefully acknowledged. The authors would like to thank Dr. Rubén Del Rosario (Principal Investigator for the Subsonic Fixed Wing Project), Dr. Nateri Madavan and Dr. James Heidmann (Associate Principal Investigators for the Subsonic Fixed Wing Project), and George Stefko (Chief, Structures and Dynamics Branch, NASA Glenn Research Center) for their support of this work. The authors would like to acknowledge Prof. Kivanc Ekici of the University of Tennessee, Knoxville for many helpful suggestions.

Trade names and trademarks are used in this report for identification only. Their usage does not constitute an official endorsement, either expressed or implied, by the National Aeronautics and Space Administration.

This work was sponsored by the Fundamental Aeronautics Program at the NASA Glenn Research Center.

Level of Review: This material has been technically reviewed by technical management.

Available from

NASA Center for Aerospace Information 7115 Standard Drive Hanover, MD 21076-1320
National Technical Information Service 5301 Shawnee Road Alexandria, VA 22312 


\title{
Aeroelastic Computations of a Compressor Stage Using the Harmonic Balance Method
}

\author{
T.S.R. Reddy \\ University of Toledo \\ Toledo, Ohio 43606 \\ Milind A. Bakhle \\ National Aeronautics and Space Administration \\ Glenn Research Center \\ Cleveland, Ohio 44135
}

\begin{abstract}
The aeroelastic characteristics of a compressor stage were analyzed using a computational fluid dynamic (CFD) solver that uses the harmonic balance method to solve the governing equations. The three dimensional solver models the unsteady flow field due to blade vibration using the Reynolds-Averaged Navier-Stokes equations. The formulation enables the study of the effect of blade row interaction through the inclusion of coupling modes between blade rows. It also enables the study of nonlinear effects of high amplitude blade vibration by the inclusion of higher harmonics of the fundamental blade vibration frequency. In the present work, the solver is applied to study in detail the aeroelastic characteristics of a transonic compressor stage. Various parameters were included in the study: number of coupling modes, blade row axial spacing, and operating speeds. Only the first vibration mode is considered with amplitude of oscillation in the linear range. Both aeroelastic stability (flutter) of rotor blade and unsteady loading on the stator are calculated. The study showed that for the stage considered, the rotor aerodynamic damping is not influenced by the presence of the stator even when the axial spacing is reduced by nearly 25 percent. However, the study showed that blade row interaction effects become important for the unsteady loading on the stator when the axial spacing is reduced by the same amount.
\end{abstract}

\section{Introduction}

Turbomachinery designers try continually to improve the performance of aircraft engine components. However, the resulting complex blade shapes and high blade loadings, sometimes lead to undesirable unsteady aerodynamic and aeroelastic characteristics that affect the operability and durability of the engine components. In addition, the push towards reducing engine weight, leads to turbomachinery designs with fewer stages that are more closely spaced and have higher loading, which results in an increase in unsteady aerodynamic interactions between blade rows. Also, to reduce weight, integrally bladed disks (blisks) are increasingly used instead of the conventional inserted blades, reducing the amount of structural damping available to suppress the aeroelastic instabilities and forced response vibrations.

Aeroelastic phenomena, which arise from the interaction between aerodynamic and structural dynamics, lead to blade vibrations. Blade vibrations can cause sudden blade failure as in flutter, or failure due to high cycle fatigue as in forced response. Flutter encountered unexpectedly during engine development and testing can result in long and costly delays in the development schedule due to the need to re-design and re-test the affected components and the engine. Forced response encountered by engines in service can cause High Cycle Fatigue (HCF) failures that lead to increased maintenance costs due to the increased need for inspection and repair. In-service engine failures can, and have, resulted in the loss of life. Also, such accidents are often followed by the grounding of an aircraft fleet, resulting in the disruption of scheduled service, increased operating costs, and ultimately in the loss of revenue. Therefore 
it is highly important that the turbomachinery is designed to avoid any aeroelastic instabilities and vibrations.

Current aeroelastic analysis of turbomachinery is focused on using time accurate computational fluid dynamic (CFD) approaches, i.e., high fidelity numerical techniques, for example, Reference 1. The methods and tools have resulted in predictions that showed good agreement with test data (Ref. 2). However the computational times required to run such codes are very high. Subsequently, research has focused on developing CFD based fast aeroelastic analysis models utilizing linearization. In these methods (Ref. 3) the governing unsteady nonlinear aerodynamic equations are written as steady nonlinear equations and unsteady linearized equations. The unsteady linearized equations are obtained by linearizing the full non-linear unsteady equations about the nonlinear steady solution. These timelinearized formulations are fast and include steady loading effects. These methods have been applied to analyze turbomachinery flows (Ref. 4). However, this formulation neglects the dynamic nonlinear effects.

To overcome the drawbacks in the methods mentioned above, harmonic balance techniques have been developed that can include dynamic nonlinear effects and at the same time can reduce time for solution (Refs. 5 and 6). In this approach, the unsteady flow is assumed to be temporally and spatially periodic, as in a turbomachinery flow. The flow variables are represented by a Fourier series in time with frequencies that are integer multiples of the original excitation frequency. The dependent variables are the coefficients of the Fourier series for each conservation variables. The Fourier series are then inserted into the unsteady fluid dynamics equations, and the resulting expressions are balanced by collecting terms with same frequency. For the equations to be satisfied, each frequency component must vanish independently. This results in a set of coupled complex partial differential equations, one for each frequency retained in the model. The method, which was later improved by storing the dependent variables at a number of sub-time levels over one period, has been applied to many configurations (Refs. 5 to 11).

Most of the applications of the models mentioned above neglected the influence of neighboring blade rows. Analytical formulations have considered rigid blades to model the interaction effects and neglected blade vibration effects. An idea to include the neighboring blade rows including blade vibration was developed in Reference 12. This formulation used aerodynamic force coefficients obtained using linear unsteady cascade aerodynamic theory. Hall et al. (Refs. 13 and 14) extended this methodology to include CFD methods based on time-linearized formulations. Finally, the harmonic balance technique was combined with the multistage formulation, to include both multistage effects and nonlinear aerodynamic effects in the unsteady aerodynamic analysis (Refs. 15 to 18 ).

In the present paper, the combined harmonic balance and multistage method, developed in References 13 to 18, is used to analyze the flutter and forced response characteristics of a compressor stage. The objectives of this paper are: (1) to apply the harmonic balance method with blade row interactions to obtain flutter and forced response characteristics of a transonic compressor stage for various operating conditions, (2) to study the effect of number of spinning modes on aerodynamic damping and unsteady loading, and (3) to investigate the effect of spacing of the blade rows on flutter and response. This is an assessment study for future application of the harmonic balance code to other multistage configurations that are being designed and tested at NASA.

\section{Formulation}

An aeroelastic model requires a consistent combination of a structural model with an unsteady aerodynamics model. The structural model used in the present analysis is obtained from a standard finite element analysis. The governing aeroelastic equations are recast in modal form. A brief description of the aeroelastic and the aerodynamic model is given below. See Reference 4 for the aeroelastic model formulation details. 


\section{Aeroelastic Model}

The aeroelastic equations of motion of $s^{\text {th }}$ blade in any blade row can be written as

$$
\left[M_{s}\right]\left\{\ddot{q}_{s}\right\}+\left[K_{s}\right]\left\{q_{s}\right\}=\left[A_{s}\right]\left\{q_{s}\right\}+\left\{A D_{s}\right\}
$$

where $\left[M_{s}\right]$ and $\left[K_{s}\right]$ are generalized mass and stiffness matrices, which are diagonal, $\left\{q_{s}\right\}$ is the generalized displacement vector, and $\left[A_{s}\right]$ is the motion-dependent generalized aerodynamic load matrix, and $\left\{A D_{s}\right\}$ is the motion-independent generalized aerodynamic load vector. The motion-dependent forces can cause flutter, and motion-independent forces result in forced response vibrations. The matrices $\left[M_{s}\right]$, $\left[K_{s}\right]$, and $\left[A_{s}\right]$ are of $N M \times N M$ size; $\left\{q_{s}\right\}$ and $\left\{A D_{s}\right\}$ are of $N M \times 1$ size.

For a tuned cascade (or rotor), in which all the blades are identical, the aeroelastic modes consist of individual blades vibrating with equal amplitudes with a fixed interblade phase angle between adjacent blades. Hence, the motion of the $s^{\text {th }}$ blade can be written as

$$
\left\{q_{s}\right\}=\left\{q_{o s}\right\} e^{i \omega t}=\left\{q_{a r}\right\} e^{i \omega t} e^{i \sigma_{r} s}
$$

Substituting in Equation (1), we obtain

$$
-\omega^{2}\left[M_{s}\right]\left\{q_{a r}\right\} e^{i\left(\omega t+\sigma_{r} s\right)}+\left[K_{s}\right]\left\{q_{a r}\right\} e^{i\left(\omega t+\sigma_{r} s\right)}=\left[A_{r}\right]\left\{q_{a r}\right\} e^{i\left(\omega t+\sigma_{r} s\right)}+\left\{A D_{r}\right\} e^{i\left(\omega t+\sigma_{r} s\right)}
$$

Since the blades are identical, the same equation is obtained for each blade and Equation (3) can be solved for $N$ different values of the interblade phase angle given by

$$
\sigma_{r}=2 \pi r / N_{\text {blades }} ; r: \quad-N_{\text {blades }} / 2 \leq r \geq N_{\text {blades }} / 2
$$

where $N_{\text {blades }}$ is the number of blades in the cascade, and $r$ is the nodal diameter $(N D)$ index.

Dropping the subscript $s$, since each blade is identical, and canceling out the exponential terms, Equation (3) can be written as

$$
-\omega^{2}[M]\{Y\}+[K]\{Y\}-\left[A_{r}\right]\{Y\}=\left\{A D_{r}\right\}
$$

\section{Stability Calculation}

An eigenvalue approach is followed to investigate flutter stability. The flutter frequencies and flutter modes are obtained from the solution. For a stability calculation (flutter), the motion-independent forces $\left\{A D_{r}\right\}$ are set to zero, and Equation (5) can be written as

$$
-\omega^{2}[M]\{Y\}+[K]\{Y\}-\left[A_{r}\right]\{Y\}=\{0\}
$$

Dividing Equation (6) with an assumed frequency, $\omega_{o}^{2}$

$$
-\left(\omega / \omega_{O}^{2}\right)[M]\{Y\}+\left[[K]-\left[A_{r}\right]\right]\{Y\} / \omega_{O}^{2}=\{0\}
$$

Rearranging, the equations can be written in the standard eigenvalue problem as:

$$
\left[\left[P_{r}\right]-\gamma\left[Q_{r}\right]\right]\left\{Y_{r}\right\}=\{0\}
$$

where

$$
\left[P_{r}\right]=\left[[K]-\left[A_{r}\right]\right] / \omega_{o}^{2}
$$




$$
\left[Q_{r}\right]=[M]
$$

and

$$
\gamma=\left(\omega / \omega_{0}\right)^{2}
$$

The solution of the above eigenvalue problem results in $N M$ complex eigenvalues of the form

$$
i \frac{\omega}{\omega_{0}}=i \sqrt{\gamma}=\bar{\mu}+i \bar{v}
$$

The real part of the eigenvalue $(\bar{\mu})$ represents the damping ratio, and the imaginary part $(\bar{v})$ represents the damped frequency; flutter occurs if $\bar{\mu} \geq 0$ for any of the eigenvalues. For the tuned cascade, the stability of each phase angle mode is examined separately. The critical phase angle is identified as the one, which results in the lowest flutter speed.

\section{Response Calculation}

The aeroelastic response of the blades induced by wakes is calculated from Equation (5) as

$$
\left\{Y_{r}\right\}=\left[\left[P_{r}\right]-\gamma\left[Q_{r}\right]\right]^{-1}\left\{A D_{r}\right\}
$$

The amplitude of each blade is obtained by summing contributions of $(Y)$ from all phase angle modes.

\section{Aerodynamic Model}

The unsteady flow equations can be solved to obtain the elements of $\left[A_{r}\right]$ and $\left\{A D_{r}\right\}$ using either a time domain approach or a frequency domain approach. Methods based on time domain approach are computationally intensive. Frequency domain approaches take out the terms associated with time by assuming a frequency for the solution, thereby reducing the computational time. In the current paper, the unsteady flow equations are solved using a frequency domain approach. Current frequency domain approaches are based on small amplitude oscillations, and assume either uniform steady flow (linear models), or a non-linear steady flow (time-linearized models). However, when the amplitude of oscillations is high, these models are not valid. A harmonic balance method can be developed that can still be in frequency domain and also can be used for high amplitude oscillations (Refs. 5 to 8). In the present formulation the harmonic balance method developed in Reference 5 is used.

\section{Harmonic Balance Method (Non-Linear Frequency Domain Model)}

In this approach, the conservation variables in the nonlinear unsteady governing equations are represented as a Fourier series in time with spatially varying coefficients, for example,

$$
\begin{aligned}
& \rho(x, y, t)=\sum_{n} R_{n}(x, y) e^{j \omega n t} \\
& \rho u(x, y, t)=\sum_{n} U_{n}(x, y) e^{j \omega n t} \\
& \rho v(x, y, t)=\sum_{n} V_{n}(x, y) e^{j \omega n t}
\end{aligned}
$$




$$
\begin{aligned}
& \rho w(x, y, t)=\sum_{n} W_{n}(x, y) e^{j \omega n t} \\
& \rho e(x, y, t)=\sum_{n} E_{n}(x, y) e^{j \omega n t}
\end{aligned}
$$

where, in principle, the summations are taken over all integer values of $n$. In practice, these series are truncated to a finite number of terms, $-N \leq n \leq+N$. Similar equations can be written for other conservation variables, and can be substituted into the Euler/Navier-Stokes equations. After substitution, the terms are grouped by frequency and require each frequency component to satisfy the conservation equations individually. Fourier components for non-negative $n$ need to be stored. If $N$ Harmonics are retained in the Fourier series representation of the flow, then $2 N+1$ coefficients are stored for each flow variable (one for the zeroth harmonic or mean flow and $2 N$ for the real and imaginary parts of each remaining harmonic). This direct approach of substituting harmonics in governing equations has been shown to increase the computational time, and not be readily applicable to viscous flows because turbulence models tend to be quite complex and cannot be readily expressed in simple algebraic forms. To alleviate these problems, solutions at several sub-time levels that span a single time period are stored (Ref. 18). These sub-time level solutions are related to each other through the time derivative term, which is approximated by a pseudo-spectral operator in the governing equations, and through boundary conditions. The complex periodicity conditions connect the sub-time levels within a blade passage, and inter-row boundary conditions connect the solutions among the blade rows. The final discretized equations are mathematically steady, and the flowfield can be solved very efficiently using multi-grid acceleration and local time stepping techniques. The computational domain is reduced to a single blade passage, with complex periodic conditions applied along the periodic boundaries. The computational time then scales as the product of the number of sub-time levels and the time required for a single steady flow calculation.

\section{Coupling of Blade Rows}

In multistage turbomachinery, waves are created because of the unsteady loading on the blades. The waves from one blade row propagate upstream and downstream, and interact with the neighboring blade rows. The neighboring blade rows emit additional waves that propagate again upstream and downstream and interact with the blade rows adjacent to them. The waves are pressure waves, vorticity and entropy waves. This type of coupling is termed as aerodynamic coupling. If blades of one of the blade rows are vibrating, they emit additional waves that depend on their vibrations. The coupling due to blade vibrations is called dynamic coupling. In the present formulation, both the couplings are included by defining spinning modes, which are pressure/ entropy/ vorticity waves of different wave numbers (Refs. 12 to 18). A brief description is given here and additional details can be found in References 13 to 18 .

Consider a stage having a stator with $B_{1}$ blades and a rotor with $B_{2}$ blades. Let the original disturbance have $k_{0}$ nodal diameters (same as $r$ in Eq. (4)) and frequency $\omega_{0}$ in the rotating frame reference. The acoustic, vortical and entropy waves from the stator blade row will interact with the rotor blade row, with the nodal diameter given by

$$
N=k_{0}+l * B_{1}+m * B_{2}
$$

with $l$ and $m$ taking on all integer values and frequencies given by

$$
\omega^{\prime}=\omega_{0}+\Omega\left(k_{0}+m^{*} B_{2}\right) \text { for the stator }
$$

and 


$$
\omega^{\prime \prime}=\omega_{0}-\Omega^{*} l * B_{1} \quad \text { for the rotor }
$$

Note that the frequencies in the stator frame of reference depend on the spinning mode index $m$ associated with scattering of waves by the rotor, and the frequencies in the rotor frame of reference depend on the spinning mode index $l$ associated with scattering of waves by the stator. At the beginning of the computation, the user specifies the spinning mode numbers, $l$ and $m$ to be used in the calculation. As an example, for one spinning mode, $(l, m)=(0,0)$; for four spinning modes $(l, m)=(0,0),(0,1),(1,0),(1,1)$; for nine modes $(l, m)=(-1 \leq l \leq 1,-1 \leq m \leq 1)$, and for $25 \operatorname{modes}(l, m)=(-2 \leq l \leq 2,-2 \leq m \leq 2)$, and so on. These mode numbers, together with the values of initial frequency, initial interblade phase angle, blade counts, and rotational speed determine the frequencies and the interblade phase angle of individual spinning modes. Unsteady solutions are generated for each of the spinning modes and combined to get the final unsteady solution.

Theoretically, $l$ and $m$ can take on an infinite number of values, which generates an infinite number of spinning modes. As the number of spinning modes in the model is increased, the unsteady solution converges to a fixed solution or at least the solution of the fundamental mode converges. However, good estimates of the unsteady flowfield can be obtained using a relatively small number of spinning modes. The present solver calculates a number of intermediate flow field solutions for each blade row depending on the number of spinning modes. However, it is important to note that the number of intermediate solutions required to obtain the final unsteady flow field is far less than the number of spinning modes selected, since many spinning modes have same frequencies and interblade phase angles differing only by $2 \pi$.

Finally, the approach can be extended to include higher harmonics of vibration amplitude as

$$
\begin{gathered}
N=n^{*} k_{0}+l^{*} B_{1}+m^{*} B_{2} \text { for nodal diameters } \\
\omega^{\prime}=n * \omega_{0}+\Omega\left(k_{0}+m^{*} B_{2}\right) \text { frequency for the stator } \\
\omega^{\prime \prime}=n^{*} \omega_{0}-\Omega^{*} l^{*} B_{1} \text { frequency for the rotor }
\end{gathered}
$$

where $n$ can be $1,2, \ldots N H$, harmonics of vibration. Note that selected values of $(n, l, m)$ are given as the input. Also, note that $n=1$ is implied in Equations (15).

\section{Results}

The configuration selected for application is designated as R67-S67 compressor stage. Experimental data is available in References 19 and 20. Rotor 67 is a transonic axial flow fan rotor tested by NASA in a rotor alone mode (Ref. 19). This rotor was designed with 22 blades with a design relative inlet Mach number at the rotor tip of 1.38 . The design rotational speed is $16,043 \mathrm{rpm}$, and the total pressure ratio is 1.63 at a mass flow of $33.25 \mathrm{~kg} / \mathrm{sec}$. To extend to a single stage, a blade row of stators (Stator 67) with 34 blades was placed downstream of the rotor row (Ref. 20). The axial distance from the trailing edge of the rotor to the leading edge of the stator is 85 percent of rotor axial chord at mid-span. This configuration was studied in Reference 16 for one operating point. In the present work, the study is extended to multiple parameters, including spinning modes, operating speeds, and aerodynamic damping calculations.

Calculations were carried out at the design rotational speed of 100 percent $(16,043 \mathrm{rpm})$ and part speed of 75 percent $(12,032 \mathrm{rpm})$. It was assumed that changes in blade geometry due to changes in rotational speed were not significant and therefore a single geometry (at 100 percent speed) was used for computations at all speeds and operating conditions. The computational grid used, generated using commercial software, is shown in Figure 1; the grid size is $193 \times 25 \times 33$ for the block that wraps around the blade airfoil (O-grid) with 193 grid points around the airfoil; 25 grid points in the circumferential 


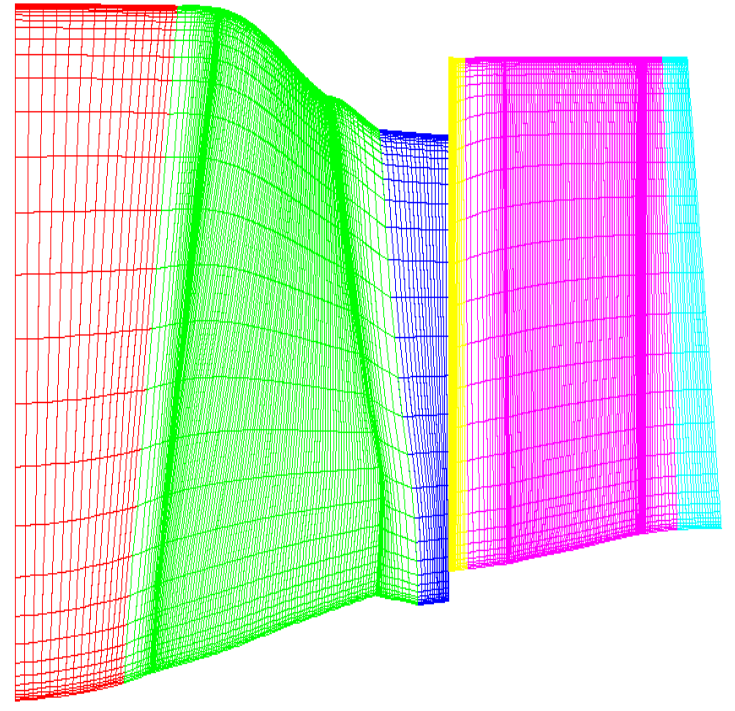

(a) Meridional view

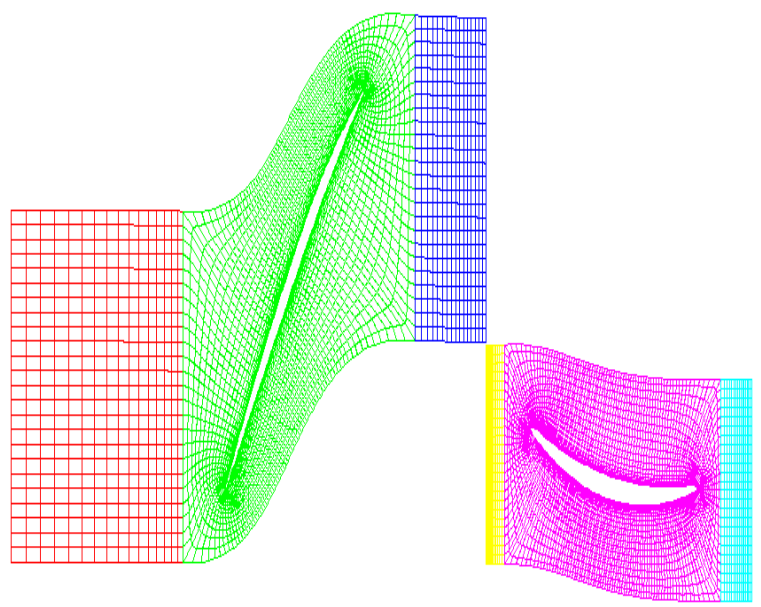

(b) Azimuthal view

Figure 1.-Rotor-stator configuration and computational grids.

direction, and 33 grid points in the spanwise direction. The grid blocks (H-grid) in the inlet and exit sections are each $17 \times 25 \times 33$ with 17 points in the streamwise direction, 25 grid points in the circumferential direction, and 33 grid points in the spanwise direction. The tip clearance was modeled with a grid with 5 points between the blade tip and casing. The same type of grids was used for the stator. However, there was no clearance grid for the stator. Figure 1 shows the rotor-stator arrangement.

Uniform inlet flow conditions (constant total pressure and temperature) were used in the computations. The exit flow conditions consisted of a static pressure prescribed at the casing and calculated at other radial locations using radial equilibrium. All solutions were obtained using a single blade passage for each blade row.

\section{Steady Solution at 100 percent Speed}

The first step in the validation of the code is to simulate the operating map of the compressor stage. Steady calculations were performed for various values of the imposed non-dimensional back-pressure, p_exit, at the exit boundary for 100 percent rotational speed. Note that for steady calculation, all the spinning mode parameters, Equation (16) are made equal to 0 ; i.e. $(n, l, m)=(0,0,0)$. Figure 2 shows the convergence of the steady computations as a plot of non-dimensional torque with iteration counter (100 iterations per counter) for the rotor. As can be noted from Figure 2, excellent convergence was obtained for all operating conditions. Similar convergence was obtained for the stator and for other computations at 75 percent speed presented later. All steady results presented here are from wellconverged solutions.

Figure 3 shows the computed operating map with 100 percent speed line. Solutions were obtained for various values of $p \_$exit to obtain the complete operating characteristic (speed line) for pressure ratios that include both stall and choke sides. Note that Reference 16 previously presented steady flow at a single operating point on the speed line to validate the code. In the present work, the flow solutions were postprocessed by a routine that calculates pressure ratio and mass flow rate.

Figure 3(a) shows the total pressure ratio versus mass flow rate calculated, between the inlet and the stage exit, by the in-house code PERF, and is designated as p1p3; published experimental measurements from Reference 20 are also included for comparison. It can be seen that the present computational results are shifted towards a lower mass flow rate (approximately $1 \mathrm{~kg} / \mathrm{s}$ ) and a lower pressure ratio (approximately 0.1 ) demonstrating that present code predicts the steady flow reasonably well. 
The predicted adiabatic efficiency is shown in Figure 4. Digitized test values from Reference 20 are also depicted in the figure. It is noted that the calculated efficiency is lower than the measured value for all the mass flow rates. The calculated peak efficiency occurs at a mass flow rate of $32.75 \mathrm{~kg} / \mathrm{sec}$ compared to the test value of $34.0 \mathrm{~kg} / \mathrm{sec}$, a difference of 3.7 percent in the mass flow rate. However, the sudden jump in the efficiency at $32.75 \mathrm{~kg} / \mathrm{sec}$ requires further study.

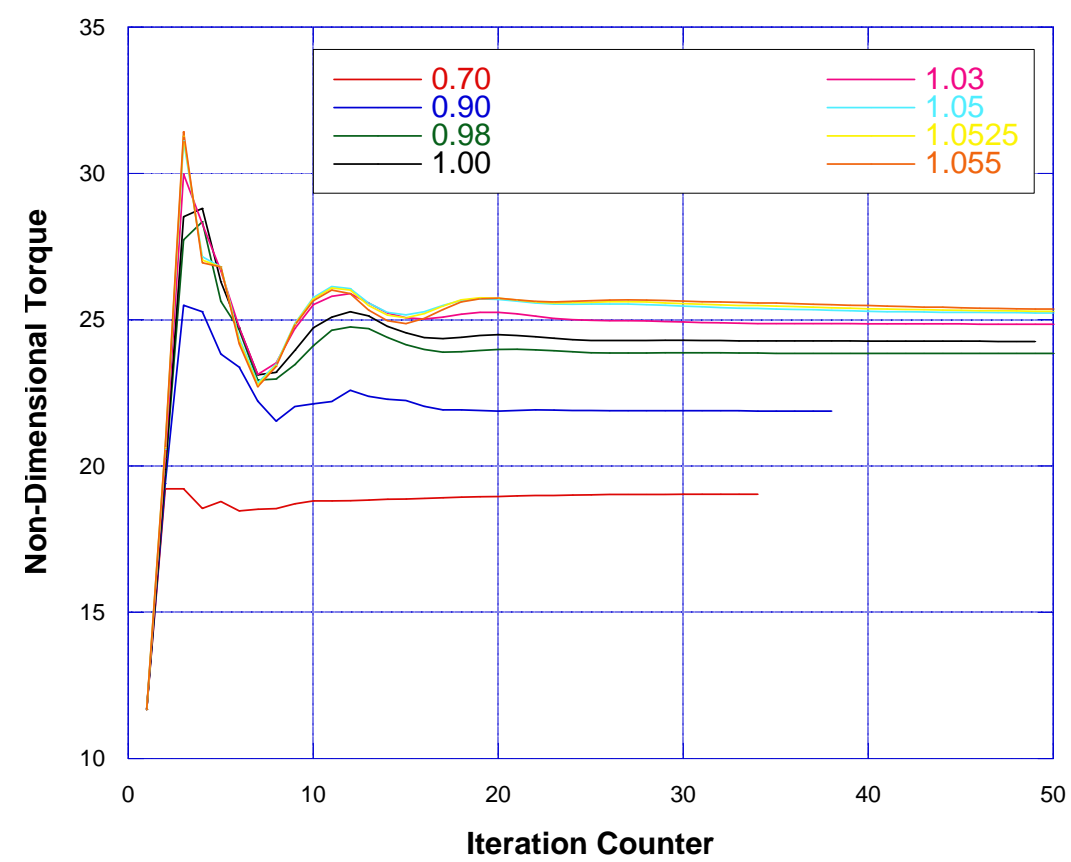

Figure 2.-Convergence of the steady solution for different values of backpressure, p_exit.

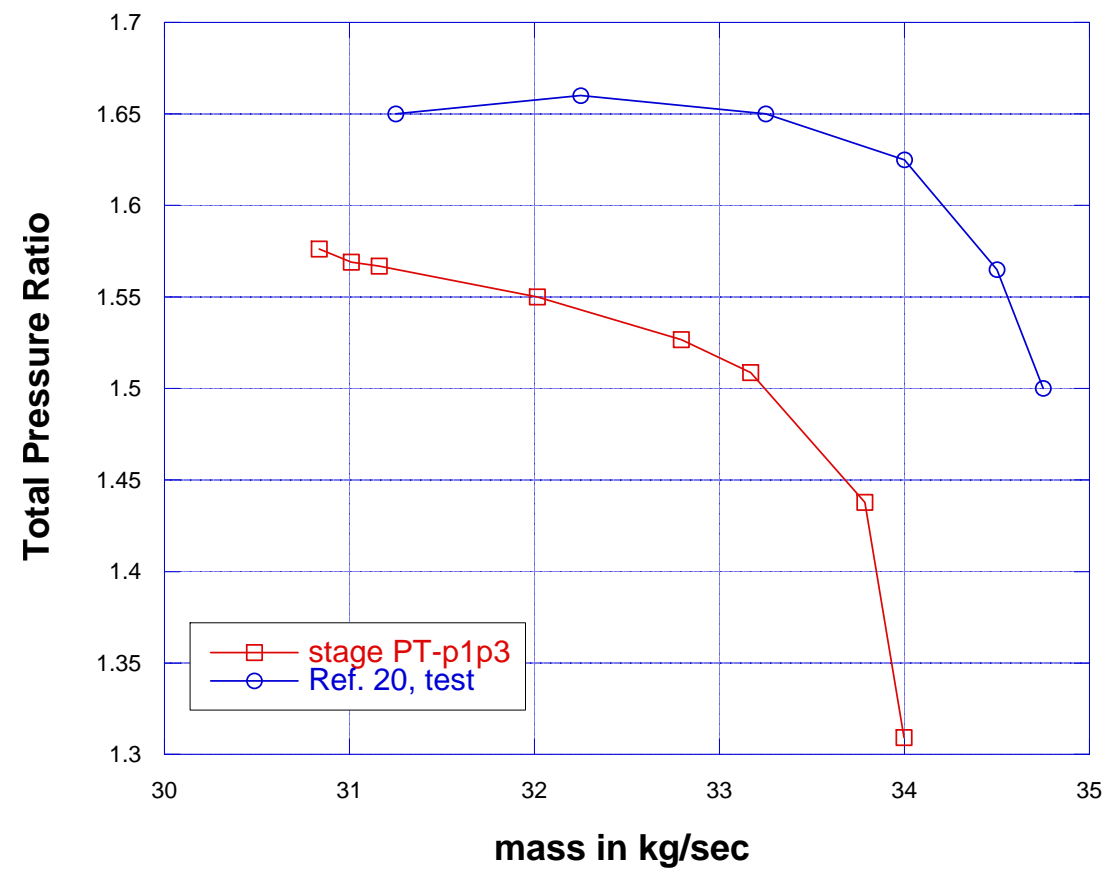

Figure 3(a).-Stage operating map. 


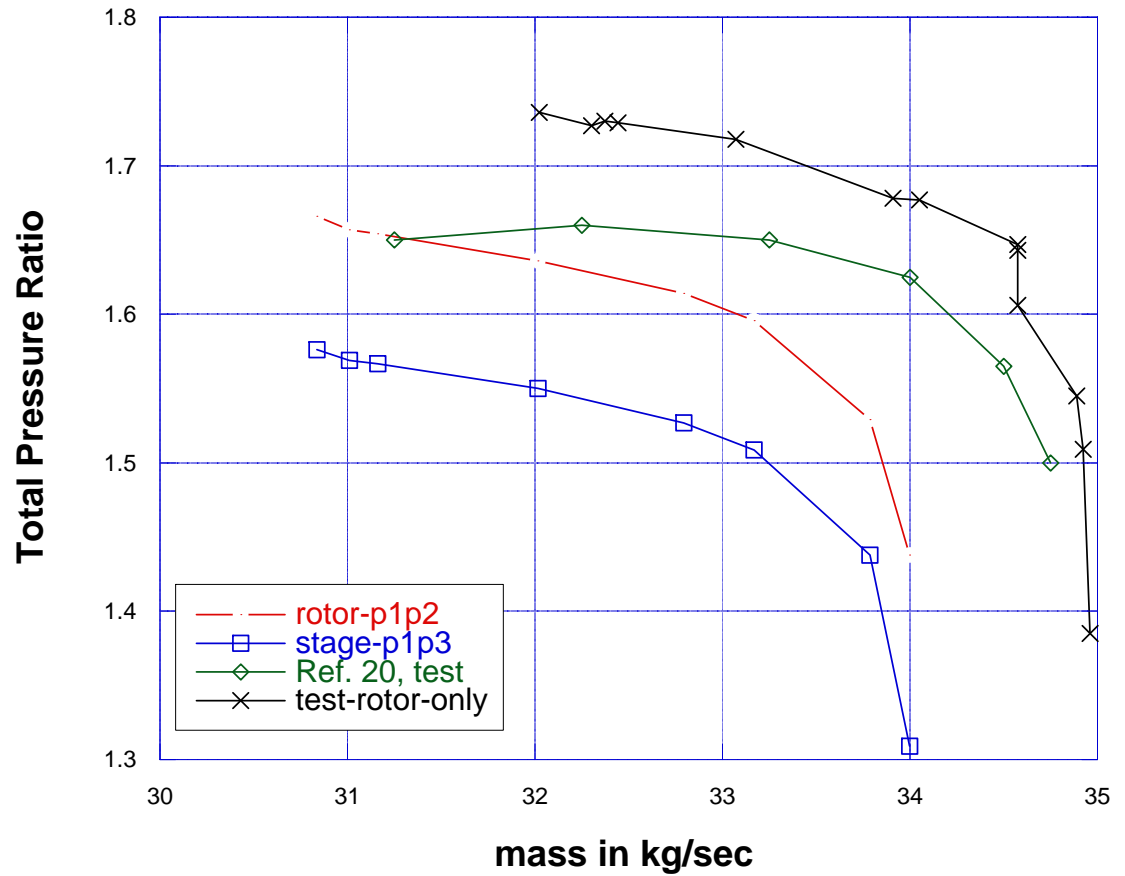

Figure 3(b).--Stage and rotor operating map.

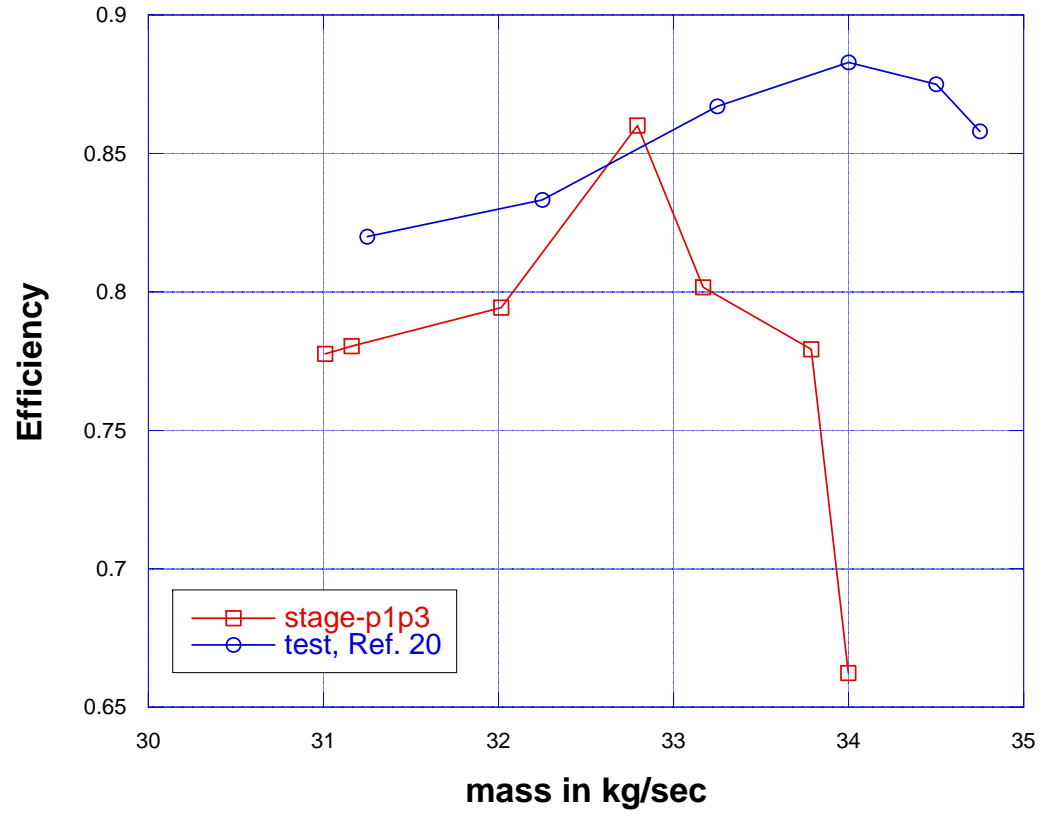

Figure 4.-Stage adiabatic efficiency.

\section{Unsteady Calculations: Flutter}

Unsteady computations were performed using the harmonic balance code to predict the aeroelastic stability of the rotor. The first vibrating rotor mode is considered in this study. As shown in Figure 5, the mode is a predominantly bending mode with a twisting component at a frequency of $554 \mathrm{~Hz}$. The prescribed blade vibration amplitude is in the linear range. All solutions were obtained using a single blade passage for each blade row. 


\section{Percent Speed}

\section{Fundamental Spinning Mode}

Results of unsteady flow calculations, obtained using the fundamental spinning mode $(n, l, m)=(1,0,0)$ as per Eq. (16)), are presented in this section. These computations were for an operating point for a nondimensional back-pressure $\mathrm{p}$ _exit of 1.0. The unsteady solution was started from the steady condition. Several nodal diameters (ND) covering the entire possible range, Equation (4), were considered. For the 22 blade rotor considered here, the nodal diameters vary from -11 to 11 as per Equation (4). Figure 6 shows the convergence of the unsteady computations as a plot of non-dimensional generalized force (imaginary part) with iteration counter (100 iterations per counter) for various nodal diameters.

Figure 7 shows the unsteady generalized forces on the rotor calculated for various nodal diameters for the same back-pressure, p_exit, of 1.0. Real values are related to the frequency, and imaginary values are related to the damping and stability of the system. The computed values compare well with the published results. For a single vibration mode, the stability is determined by the imaginary part of the generalized force, and Figure 7 shows that the stability varies significantly with nodal diameter, it can be seen that the imaginary part of the generalized force has the lowest absolute value for $N D=0,1$, and 2 .

The damping of the system is obtained from the generalized forces by solving the eigenvalue problem given in Equation (8). The damping obtained from Equation (12) for various nodal diameters is plotted in Figure 8. Note that the damping values presented in the figures are opposite in sign to the damping ratio (real part of the eigenvalue, $\bar{\mu}$ ) in Equation (12). Structural damping is not considered in the calculations; therefore, the calculated damping from Equation (12) is entirely aerodynamic damping. It can be seen that the damping is the lowest for $N D=0,1$, and 2 , and varies from 0.5 to 3.5 percent for the range of nodal diameters.

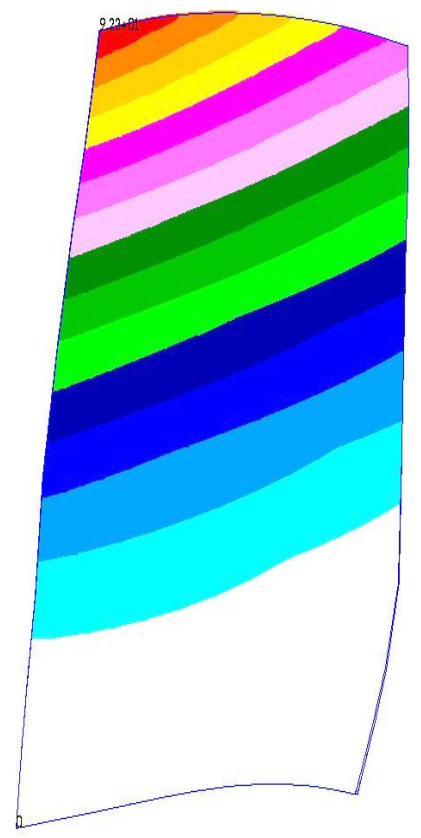

Figure 5.-First mode shape of the rotor blade $(554 \mathrm{~Hz})$.

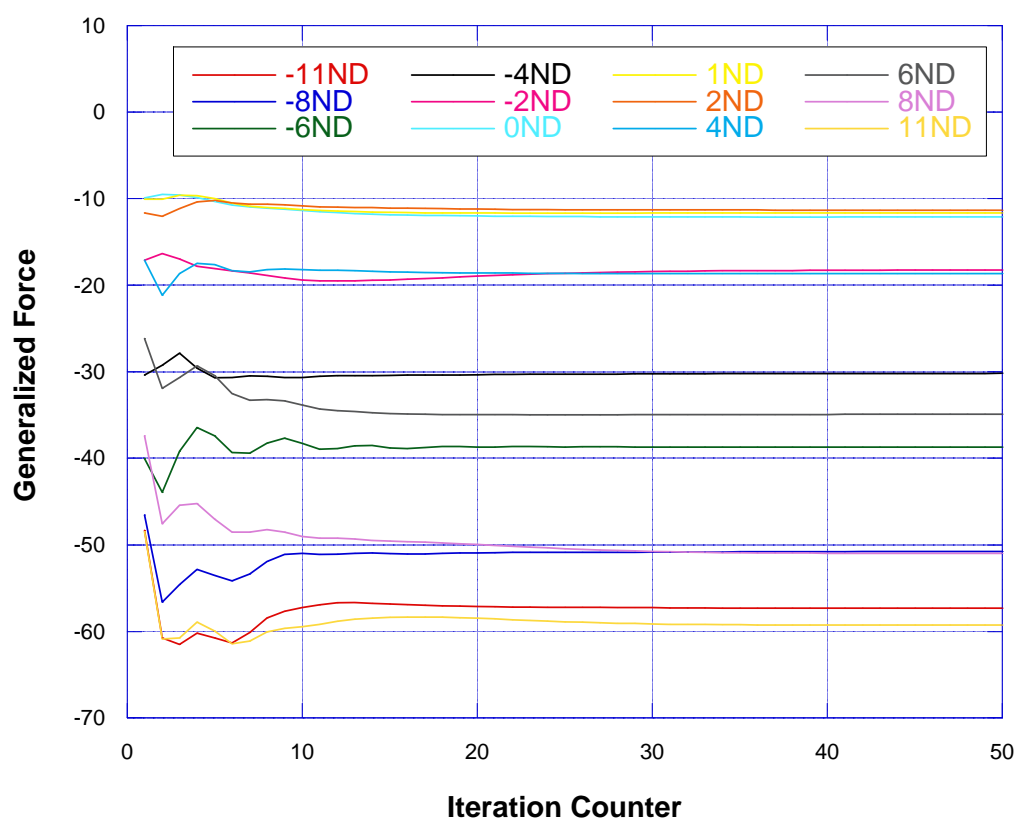

Figure 6.-Convergence of the unsteady generalized force (imaginary part). 


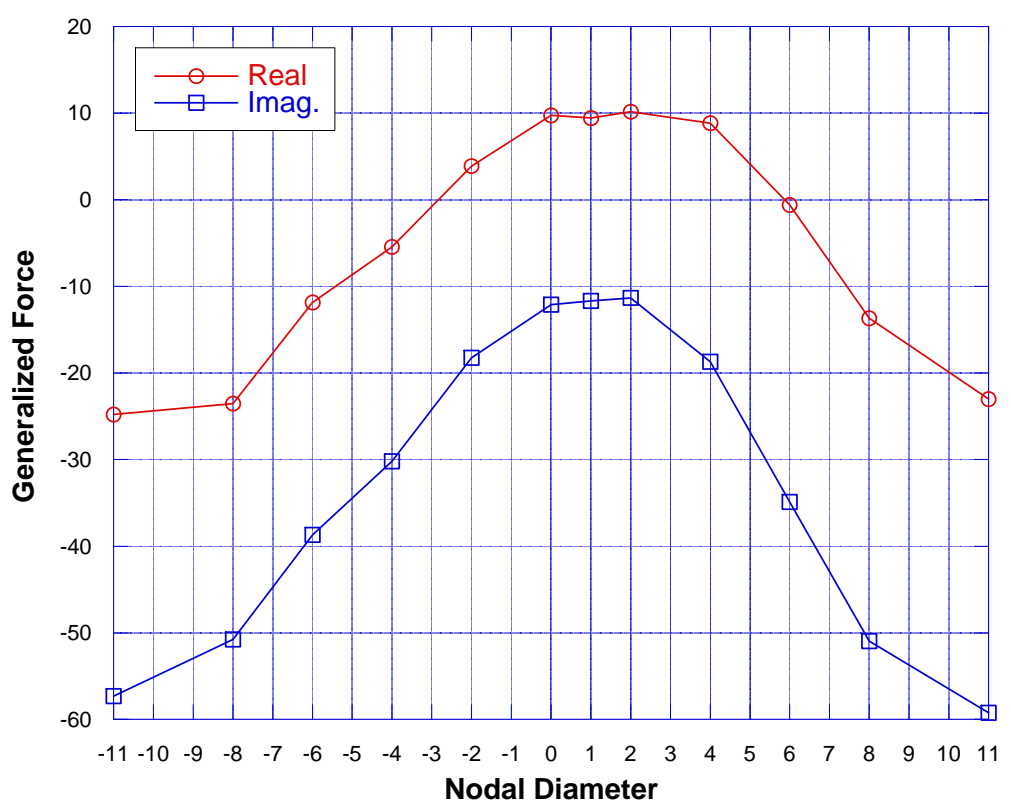

Figure 7.-Rotor generalized force (real and imaginary parts); p_exit=1.0.

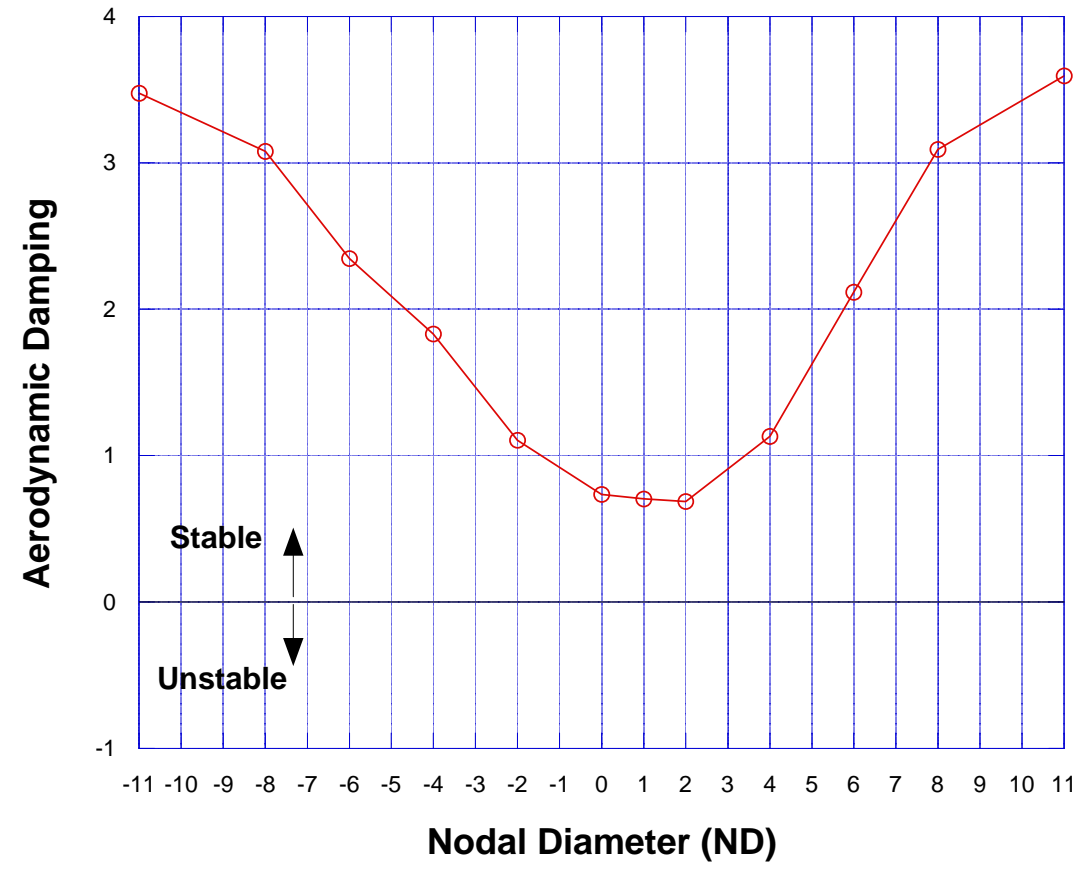

Figure 8.-Rotor aerodynamic damping at 100 percent speed; p_exit=1.0.

\section{Additional Spinning Modes}

In addition to the fundamental spinning mode, $(n, l, m)=(0,0,0)$, additional spinning modes, are included in the analysis to study their effect on improving the accuracy of the unsteady flow solution. The analysis is still done at small amplitude oscillations by including only one harmonic $(n=1)$. The modes selected are $(n, l, m)=(1,0,0),(1,0,1),(1,1,0)$ and $(1,1,1)$ as per Equations $(16)$. Figure 9 shows the generalized forces calculated with the fundamental mode (designated nmod2) and extra spinning modes (designated nmod=5). It can be seen that the addition of more spinning modes in the solution did not affect the generalized force. Additional solutions were also obtained by including more modes (nine 
modes), but they did not show any appreciable change in the generalized force. These results are therefore not included here. The results in Figure 9 clearly show that for this configuration, at the conditions considered, the stator is not influencing the rotor in any significant way. Therefore, in the following sections, only the results obtained using two spinning modes are presented.

\section{Effect of Back-Pressure, p_exit}

Figure 10 shows the aerodynamic damping for back-pressure of 1.0 and 1.055 . It can be noted that the aerodynamic damping calculated for all nodal diameters is positive. The stability varies slightly with back-pressure. Further, with the change in back-pressure from peak-efficiency towards stall, it can be seen that the damping decreases and the graph moves towards the zero damping line. The nodal diameters corresponding to lowest damping remain unchanged $(N D=0,1,2)$. However, the reduction in damping with back-pressure is marginal. For the last computed point near stall ( $\mathrm{p} \_$exit=1.055), the damping remains positive, indicating that no flutter is expected for the 100 percent speed. This result is consistent with the rig test, in which no flutter was observed.

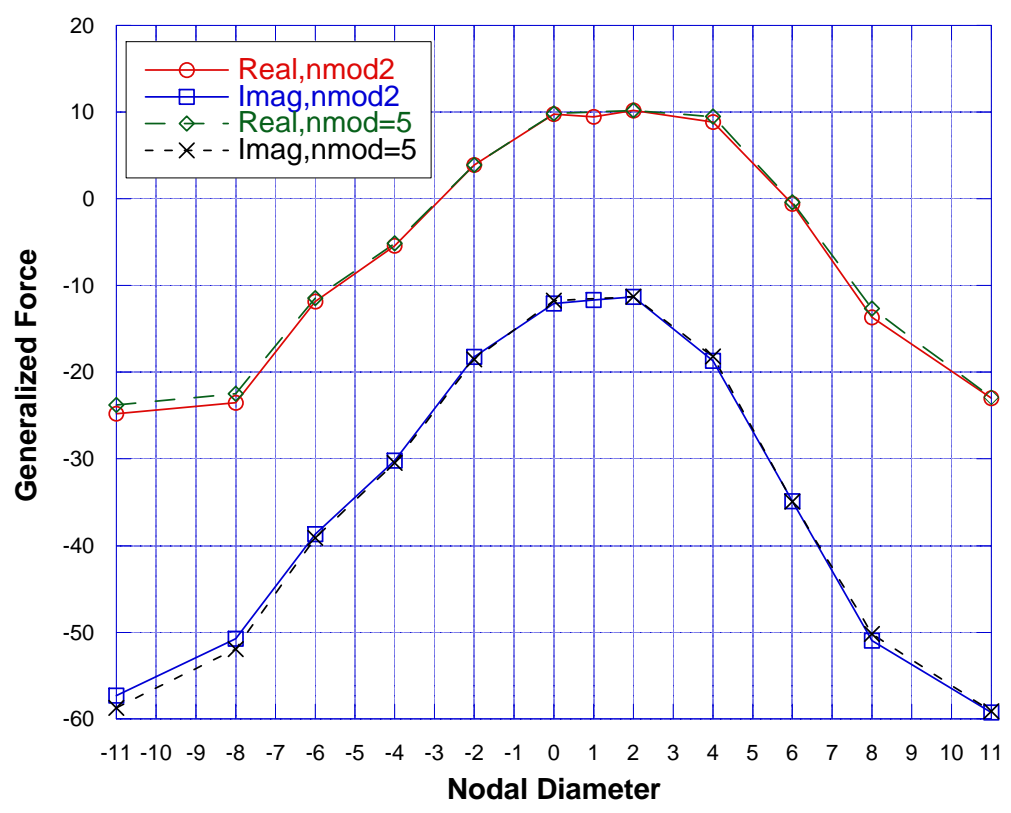

Figure 9.-Effect of spinning modes on rotor generalized forces.

Fundamental spinning mode $(\mathrm{nmod} 2)$ and additional spinning modes (nmod=5) 


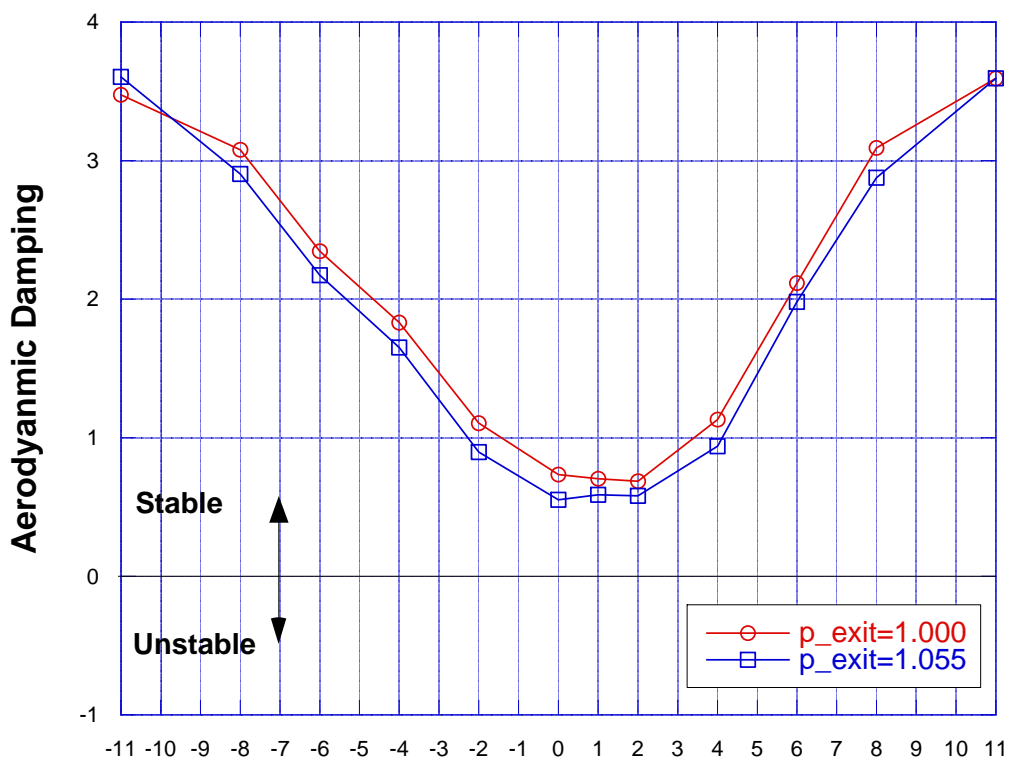

Nodal Diameter (ND)

Figure 10.-Effect of back-pressure on damping.

\section{Blade Row Spacing Effects}

The results presented in the preceding sections showed that the blade row interaction effects for this configuration are marginal. Hence, to increase the interaction between blade rows, the axial spacing between the rotor and stator is reduced from 85 percent of rotor chord to 65 percent of rotor chord (approximately 25 percent reduction in axial spacing). The revised operating map for this configuration is shown in Figure 11 with the results for the original spacing ( 85 percent rotor chord) designated as sp1, and the results for the reduced spacing ( 65 percent rotor chord) designated as sp2. It can be seen that the rotor speed line moved up towards higher pressure ratios for the same mass flow rate. This result is consistent with the expected effect of a reduction in blade row axial spacing.

Figure 12 shows the generalized force obtained when the spacing between the rotor and stator is reduced by 25 percent. Only the fundamental mode is included in these calculations since previous results indicated no significant effect of the additional spinning modes. In Figure 12, it can be seen that the generalized forces varied somewhat for some nodal diameters such as $N D=8$ and 11 . However, for the nodal diameters with the least damping, there is minimal change in the unsteady generalized force on the rotor even with the 25 percent reduction in spacing. It is seen that the stator has minimal influence on the rotor unsteady loading. It is expected that the stator may be more influenced by the rotor than vice versa and this possibility will be examined later by comparing the unsteady loading on the stator for both the spacings.

\section{Percent Speed}

To examine the possibility of part-speed flutter, computations were carried out at 75 percent rotational speed $(12,032 \mathrm{rpm})$. Figures 13 and 14 show the operating map with 75 and 100 percent speed lines. The 75 percent speed line is shifted to lower mass flow rate and pressure ratio, as expected. The drop in the pressure ratio is about 0.4 , similar to published data for similar configurations. The reduction in mass flow rate is about $8 \mathrm{~kg} / \mathrm{sec}$, which is also similar to published data for similar configurations. The peak efficiency occurs at a pressure ratio of $25.65 \mathrm{~kg} / \mathrm{sec}$ for a pressure ratio of 1.290 . 


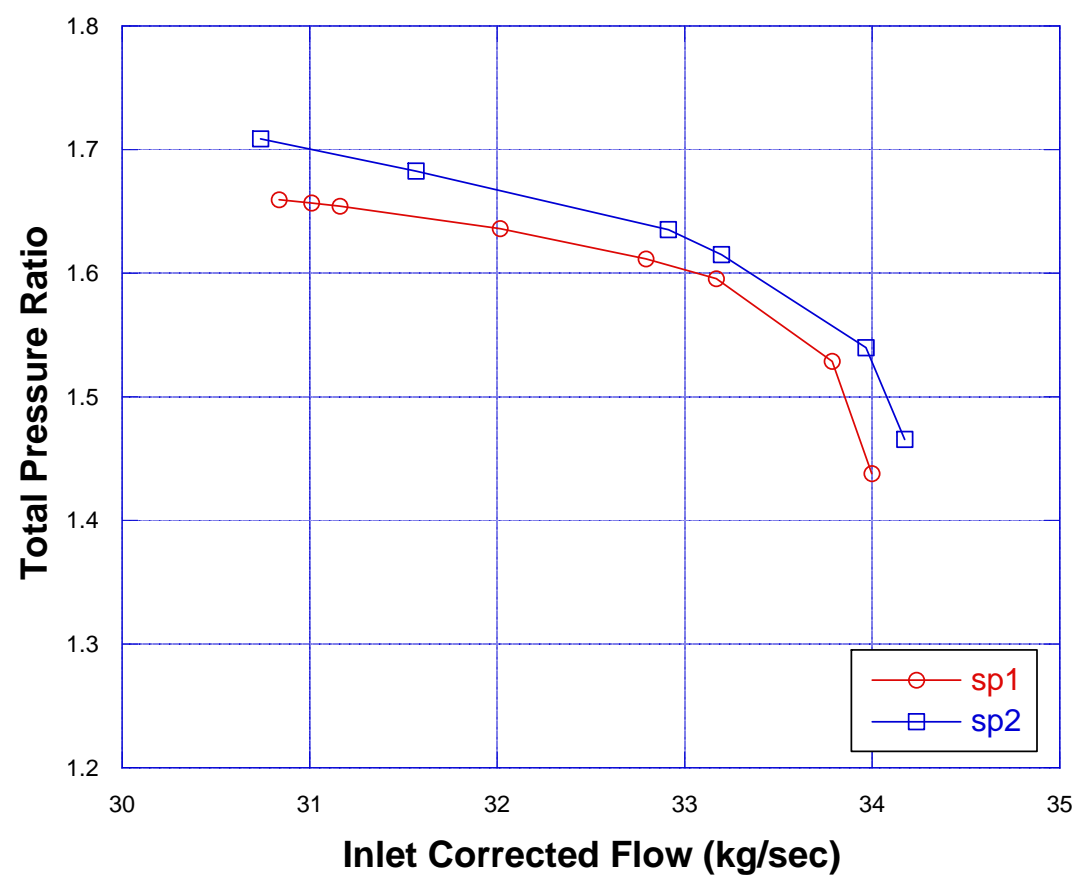

Figure 11.-Effect of spacing on rotor map; original spacing (sp1), reduced spacing (sp2).

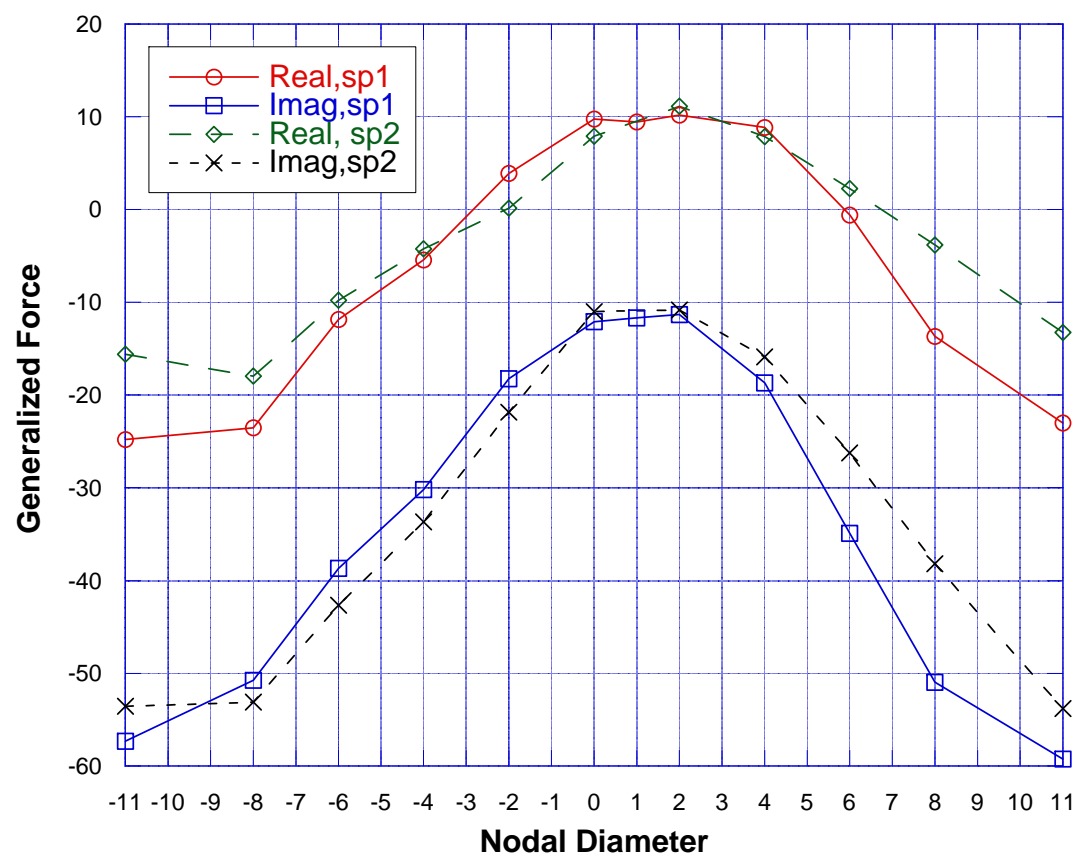

Figure 12.-Effect of spacing on generalized force. 


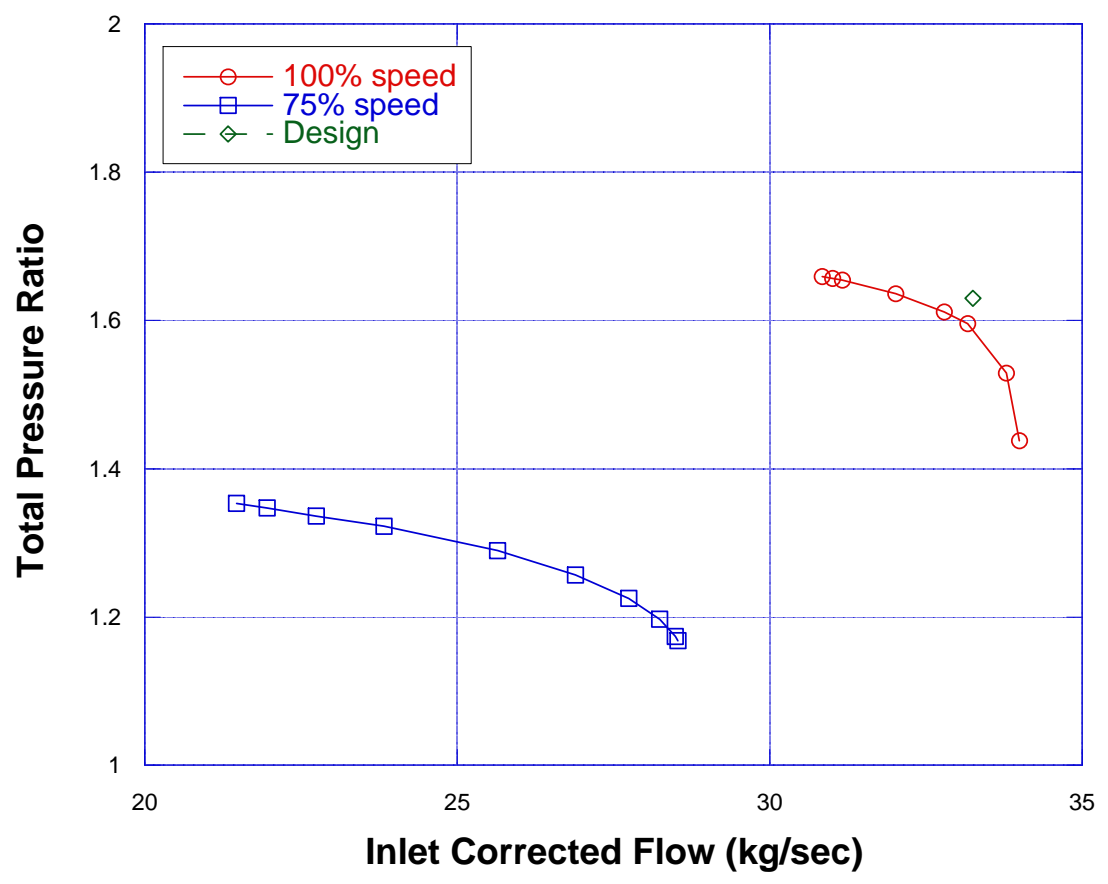

Figure 13.--Rotor operating map.

Figure 15 shows the variation of aerodynamic damping with nodal diameter at 75 percent rotational speed and for the original blade row spacing (sp1). The vibration frequency is $479 \mathrm{~Hz}$ for this speed. The figure shows the calculated aerodynamic damping for two values of back-pressure (p_exit). The lower value $(0.85)$ is near peak efficiency, and the higher value $(0.92)$ is near stall. It can be seen that the damping of the rotor is reduced at 75 percent speed as compared to the damping at 100 percent speed (Fig. 10), but only for high nodal diameters. At the low nodal diameters, the damping levels are nearly unchanged between 100 and 75 percent speeds.

To examine the stability characteristics at near-stall conditions, the aerodynamic damping at 100 percent speed and 75 percent speed is compared in Figure 16. The corresponding operating points near stall are $p_{-}$exit $=1.055$ for 100 percent speed and $p_{-}$exit $=0.92$ for 75 percent speed. It can be seen that the lowest value of damping near nodal diameters $(0,1$, and 2$)$ remained the same, even though the highest value of the damping dropped from 3.5 percent at 100 percent speed to 2.5 percent at 75 percent speed line. Thus, for this configuration, the lowest aerodynamic damping levels are nearly the same at both the design and part speeds. Further, the nodal diameters corresponding to the lowest damping are also the same for design and part speeds. 


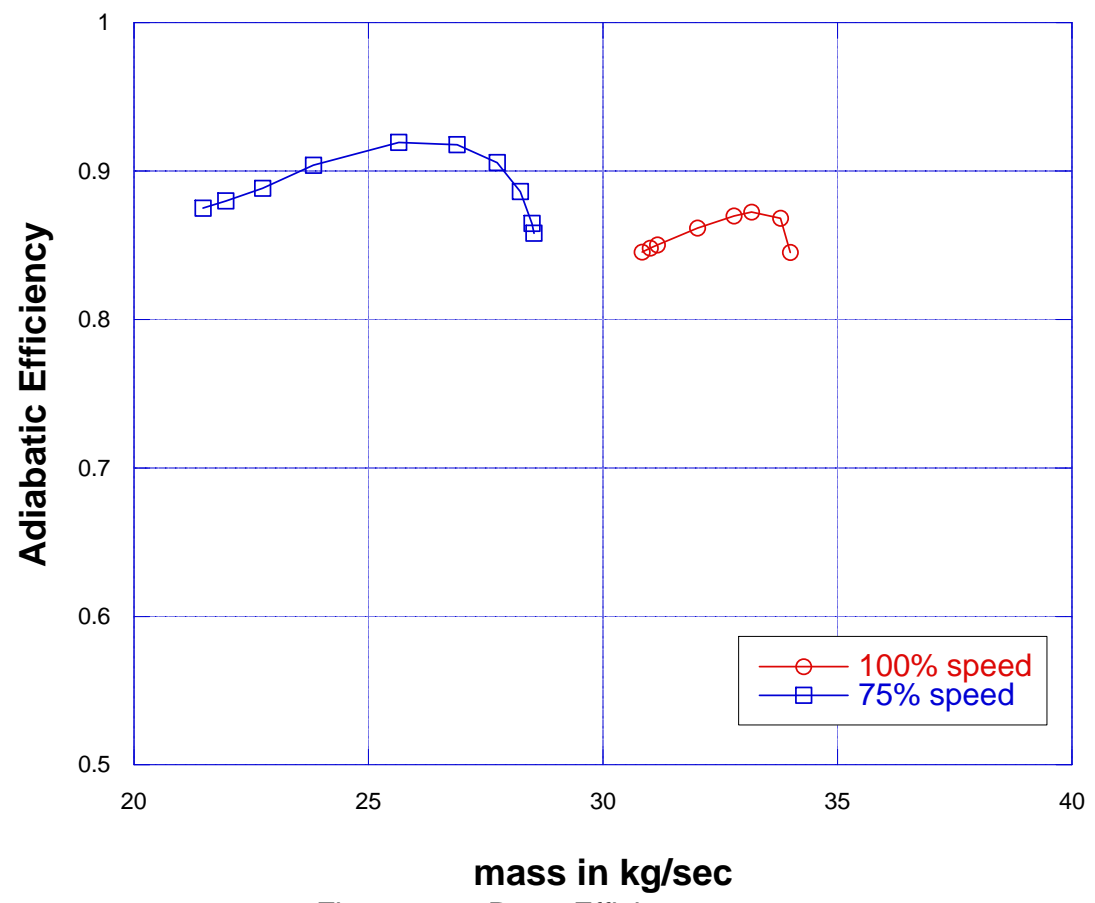

Figure 14.-Rotor Efficiency map.

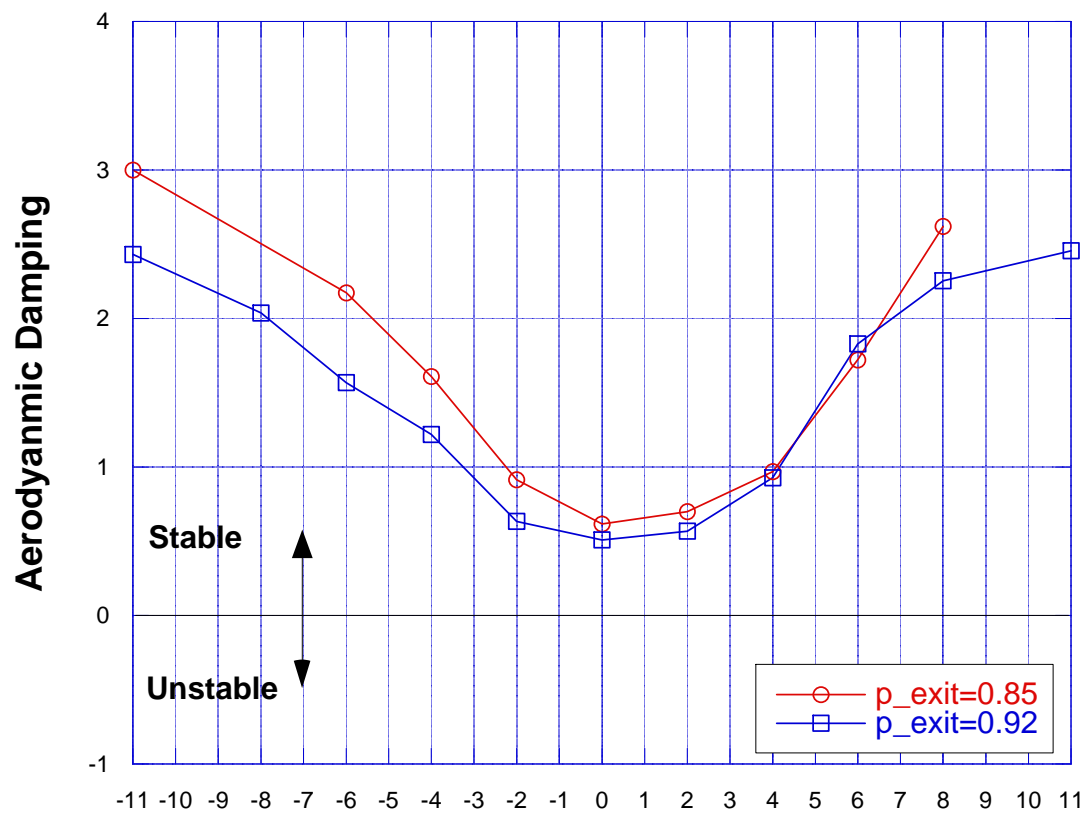

Nodal Diameter (ND)

Figure 15.-Effect of back-pressure (p_exit) on aerodynamic damping at 75 percent speed. 


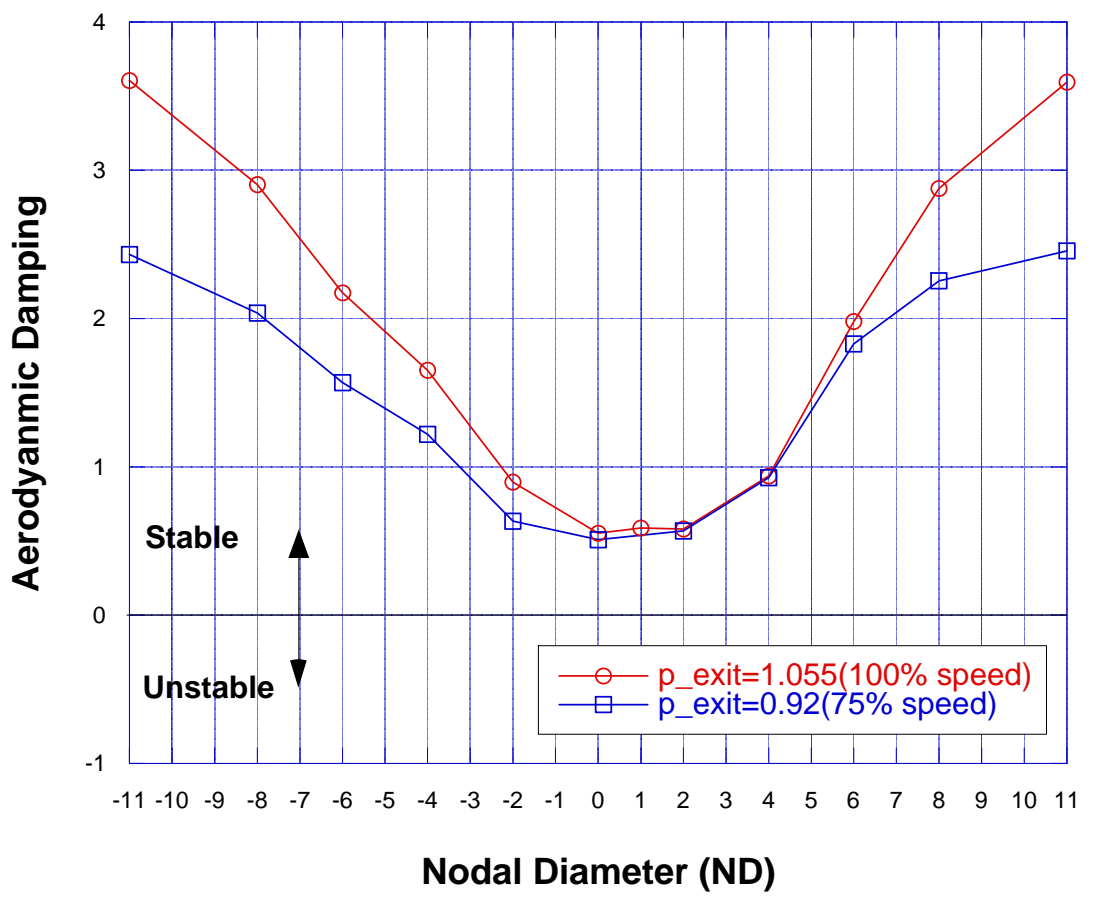

Figure 16.-Effect of speed on aerodynamic damping for back-pressures near stall.

\section{Unsteady Calculations: Response}

For the forced response vibrations of the stator blades, calculations were carried without blade vibrations. The focus is on the forcing function acting on the stator blades due to the presence of the rotor. A single blade passage is used for each blade row in this response study similar to the flutter calculations described earlier. For most of the calculations, four spinning modes are selected for the response solution: $(n, l, m)=(0,0,0),(0,1,1),(0,1,0)$ and $(0,1,1)$ as per Equation $(16)$. This selection results in single blade passing frequency. Note that $n=0$ for all the spinning modes since blade vibration is not included in response calculations. Additional calculations were also performed with 9 and 16 modes, which resulted in two and three discrete non-zero frequencies, following Reference 21 . The frequencies of the forcing function will be the blade passing frequency and its higher harmonics. For this case, the frequency will be $5,882 \mathrm{~Hz}$, which is about 10 times the vibration frequency used in the rotor flutter study.

Figure 17 shows the mean (time-averaged) pressure distribution on the blade surface at 90 percent span of the stator blade row obtained with 4 and 9 modes, and for the original blade row spacing (sp1). Also shown in the figure is the pressure distribution for the multiblade row steady solution $(n, l, m)=(0,0,0)$. The mean surface pressure obtained from the unsteady computations is slightly different than the one obtained from the steady computation, although the differences are small. The results from solutions with 4 and 9 modes are nearly identical, indicating that the mean pressure solution has converged with respect to the number of modes.

Figure 18 shows the instantaneous unsteady pressure contours at 90 percent span from 4 mode solution. Although the actual computations are performed over a single blade passage in each blade row, multiple passages are included in Figure 18 for better visualization of the flow features. The contour plots show no significant flow features that may cause a strong interaction between the blade rows.

Figure 19 shows the real and imaginary parts of the first harmonic of the unsteady pressure at 90 percent span of the stator. Small differences are seen between the solutions for 4 and 9 modes. The solution with 9 modes shows slight improvement in the spatial resolution of the pressure distribution, as 
can be seen in Figure 19(a) from leading edge to 40 percent chord. Based on these representative results, it is inferred that four modes are enough to capture the primary unsteady effect for the present study.

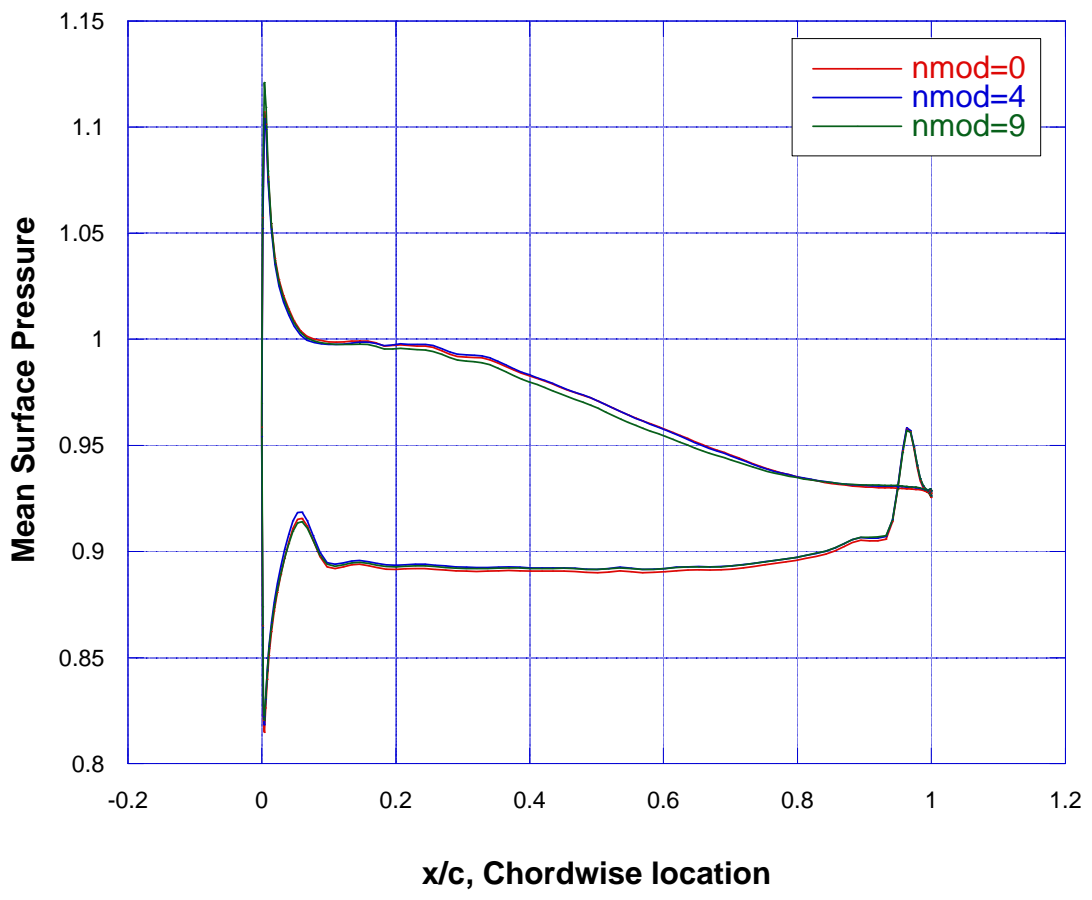

Figure 17.-Mean surface pressure distribution at 90 percent span of the stator blade, p_exit=1.0.

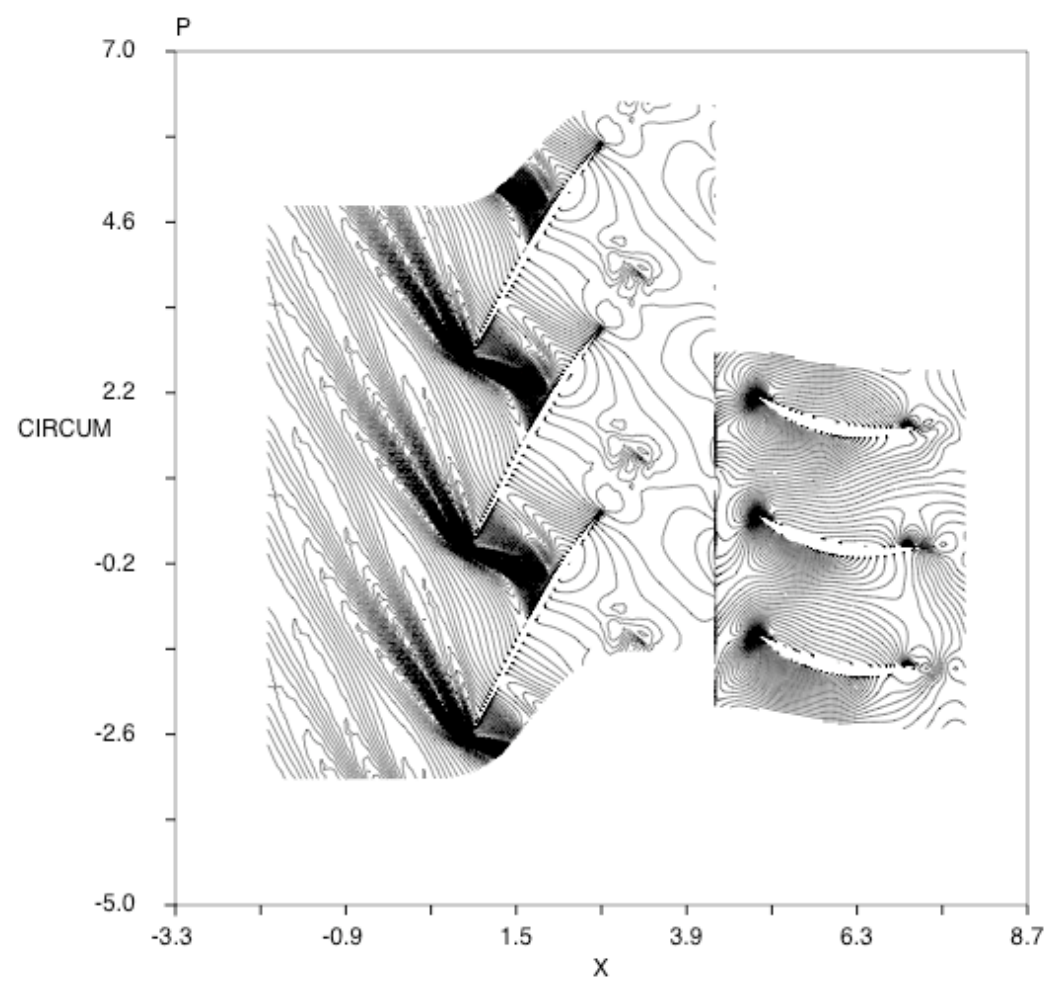

Figure 18.- Instantaneous pressure contours at 90 percent span on stator blade; 4 mode solution, p_exit=1.0. 


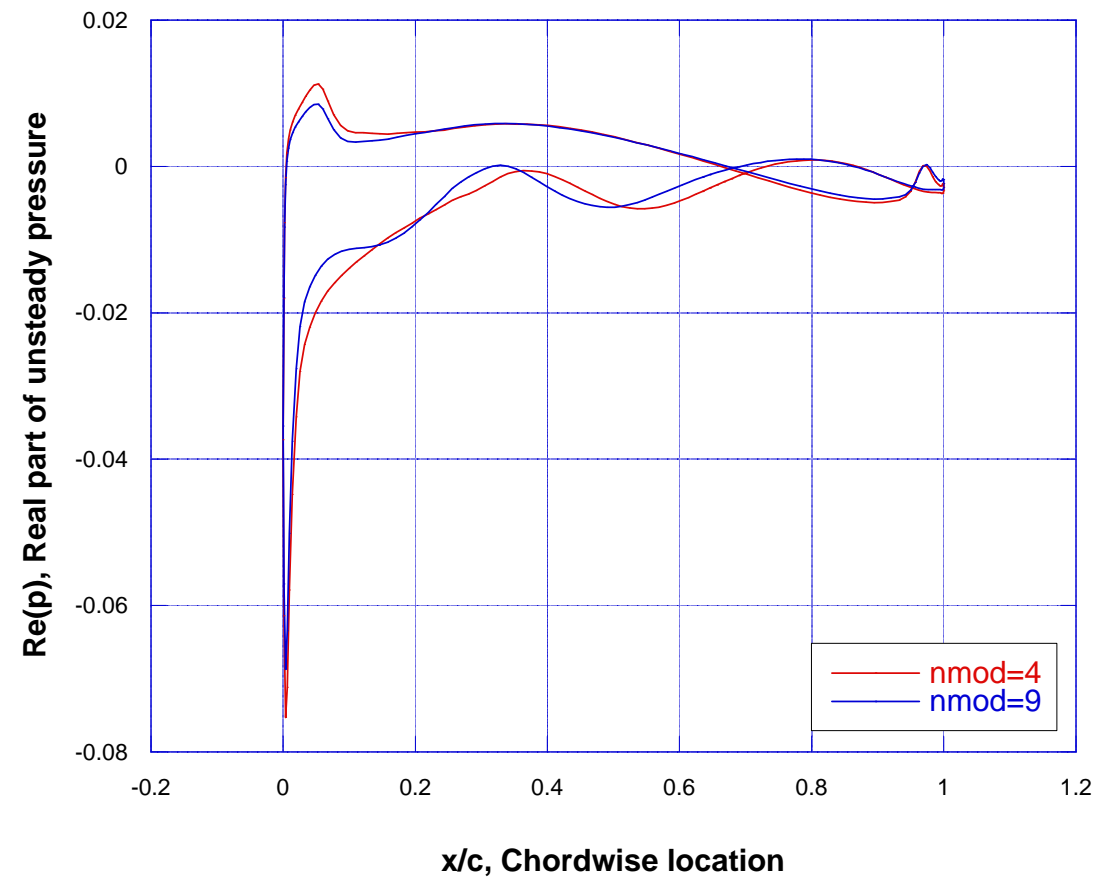

(a) real part

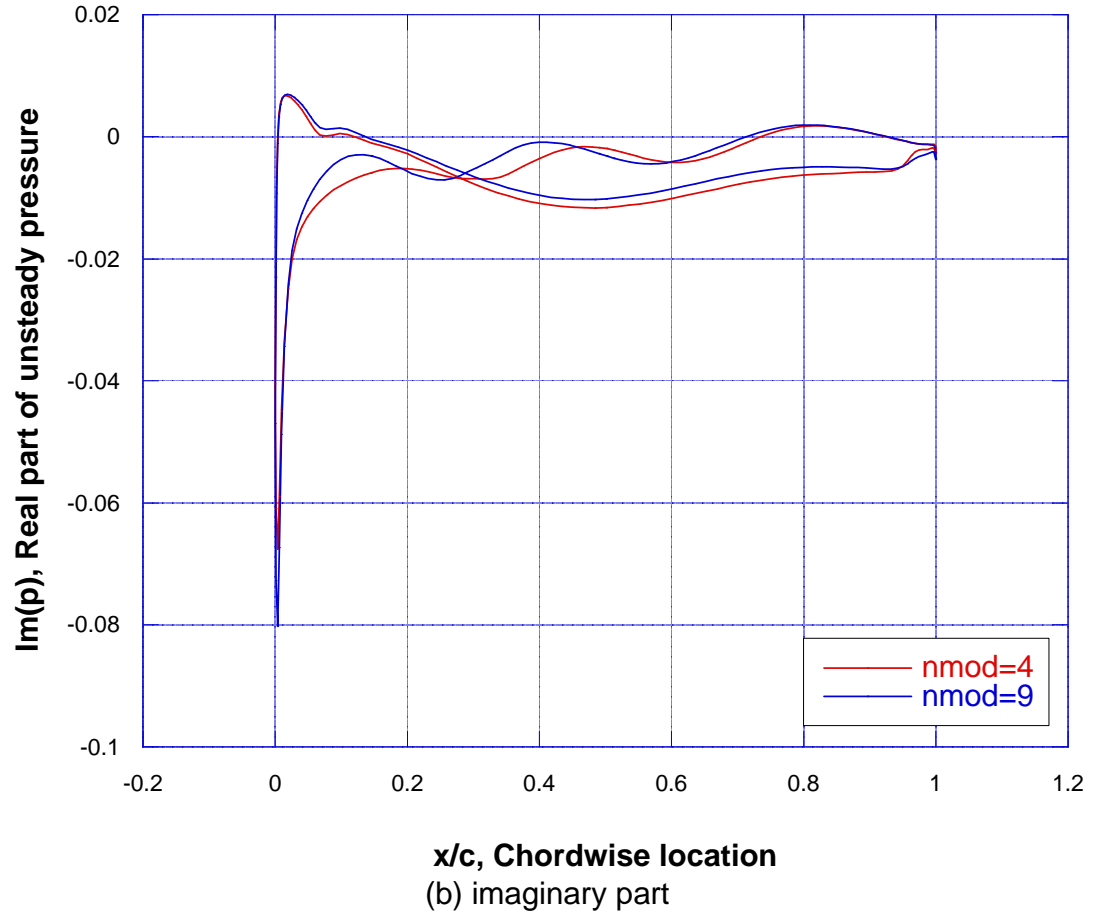

Figure 19.-Unsteady first harmonic surface pressure distribution at 90 percent span of the stator blade, p_exit $=1.0$ 
Figure 20 shows unsteady surface pressure distribution at 90 percent span of the stator blade row for the original blade row spacing (sp1) and reduced blade row spacing (sp2). Four modes are used for both these solutions. There are notable differences in the unsteady loading for the two spacings considered. Based on these results, it may be inferred that the unsteady forcing function on the stator is changed by the reduction in the axial spacing between the two blade rows. A comparison of the generalized force for the two axial spacings will be required to quantify the impact of spacing on stator blade response.

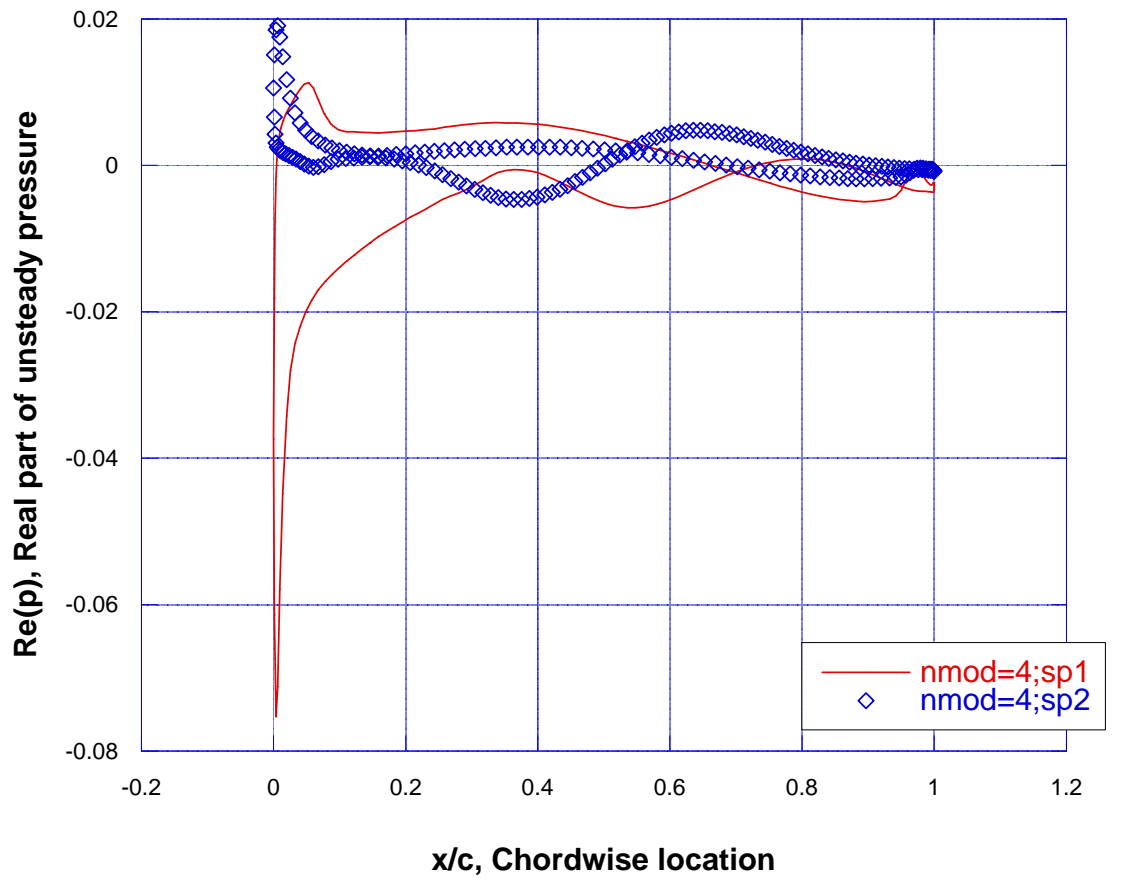

(a) real part

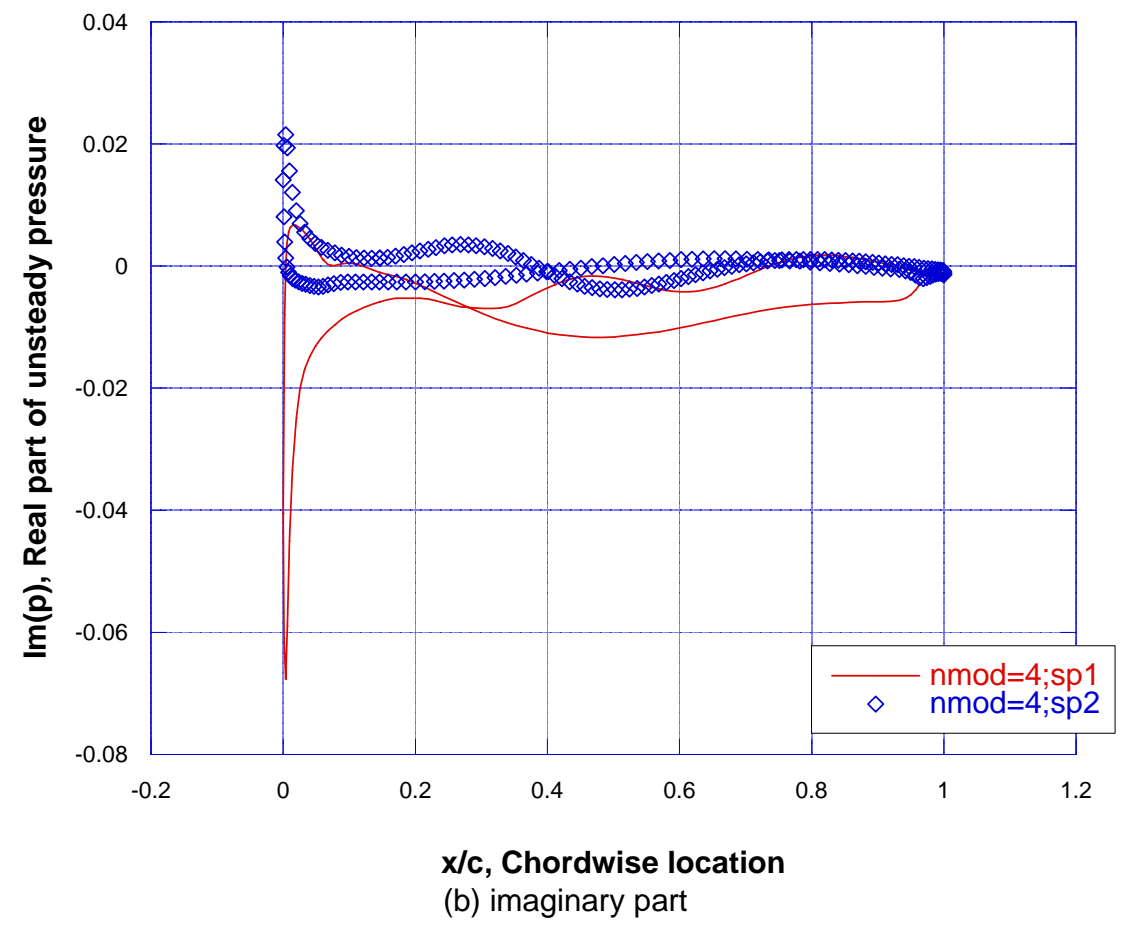

Figure 20.-Unsteady first harmonic surface pressure distribution at 90 percent span of the stator blade for two axial spacings; $p \_$exit=1.0 


\section{Conclusion}

A harmonic balance method has been applied to analyze flutter and response of a compressor rotorstator configuration. The unsteady aerodynamic analysis includes blade row interaction effects through the inclusion of coupling modes between blade rows. The compressor configuration analyzed was previously tested at NASA but blade vibrations were not measured or studied in the experiment. The steady calculations were done for multiple operating points and rotational speeds than those published in literature. The present calculations predicted the steady loading close to that of the design and the value measured in experiment.

Unsteady flutter calculations were performed for the rotor-stator configuration. In this study, the first vibration mode of the rotor with amplitude of vibrations in the linear range was considered. Aerodynamic damping results showed a very weak variation with back-pressure or mass flow rate. Detailed calculations indicated that the rotor was stable for the rotational speeds and mass flow rates considered. Increasing the number of coupling modes used in the unsteady solution did not change the results obtained using only the fundamental coupling mode. A reduction of the axial spacing between rotor and stator by 25 percent showed no significant effect on the aerodynamic damping results. For all the cases studied, the low nodal diameters of $N D=0,1,2$ were found to have the lowest aerodynamic damping.

The unsteady loading on the stator was also calculated using the present harmonic balance method. Solutions with 4, 9, and 16 coupling modes were obtained and compared. It was noted that the mean loading from the unsteady solution was slightly different from loading from the solution with no coupling modes. Small differences were seen between the solutions for 4 and 9 modes. The solution with 9 modes shows slight improvement in the spatial resolution of the pressure distribution. Based on these representative results, it is inferred that four modes are enough to capture the primary unsteady effect for the present study. Reduction of the axial spacing between rotor and stator by 25 percent showed considerable effect on the unsteady loading on the stator. A comparison of the generalized force for the two axial spacings is planned to quantify the impact of spacing on stator blade response.

Follow-on work is planned to include other modes of rotor vibration for the R67-S67 compressor configuration and response calculations of the stator blades. Further application and validation of the harmonic balance method is planned for the unsteady analysis of multistage turbomachinery.

\section{References}

1. Chen, J.P., "Unsteady Three Dimensional Thin-Layer Navier-Stokes Solutions for Turbomachinery in Transonic Flow," Ph.D. Dissertation, Dept. of Aerospace Engineering, Mississippi State University, MS, Dec. 1991.

2. Bakhle, M.A., Srivastava, R., Keith, Jr., T.G., and Stefko, G.L., "Development of an Aeroelastic Code Based on an Euler Navier-Stokes Aerodynamic Solver," NASA TM-107362, 1996.

3. Montgomery, M.D. and Verdon, J.M., "A Three Dimensional Linearized Unsteady Euler Analysis for Turbomachinery Blade rows,” NASA CR-4770, Mar. 1997.

4. Reddy, T.S.R., Bakhle, M.A., Trudell, J.J., Mehmed, O. and Stefko, G.L., "LINFLUX-AE: A Turbomachinery Aeroelastic Code Based on a 3-D Linearized Euler Solver," NASA/TM-2004212978, May 2004.

5. Hall, K.C., Thomas, J.P., and Clark, W.S., "Computation of Unsteady Nonlinear Flows in Cascades using a Harmonic Balance Technique," AIAA Journal, Vol. 40, No. 5, 2002, pp. 879-886.

6. Ning, W. and He, L., "Computation of Unsteady Flows Around Oscillating Blades Using Linear and Non-Linear Harmonic Euler Methods, Journal of Turbomachinery," Vol. 120, No. 3, 1998, pp. 508-514.

7. Hall, K.C., Thomas, J.P., Ekici, K., and Voytovych, D.M., "Frequency Domain Techniques for Complex and Nonlinear Flows in Turbomachinery," AIAA Paper 2003-3998. 33rd AIAA Fluid Dynamics Conference and Exhibit, 23-26 June 2003, Orlando, FL. 
8. Ekici, K. and Hall, K.C., "Nonlinear Frequency-Domain Analysis of Unsteady Flows in Turbomachinery with Multiple Excitation Frequencies," AIAA Journal Vol. 46, No. 8, Aug. 2008.

9. Bakhle, M.A., Thomas, J.P., and Reddy, T.S.R., "Fan Flutter Computations Using the Harmonic Balance Method," NASA/TM-2009-215301, AIAA-2008-4743, 44th Joint Propulsion Conference and Exhibit, Hartford, CT, July 21-23, 2008.

10. Bakhle, M.A., Reddy, T.S.R. and Stefko, G.L., "Comparisons of Flutter for an Experimental Fan, International Society of Air Breathing Engines," ISABE-2009-16, Sep. 7-11, 2009, Montreal, Canada.

11. Bakhle, M.A. and Reddy, T.S.R., "Harmonic Balance Computations of Fan Aeroelastic Stability," International Forum on Aeroelasticity and Structural Dynamics, IFASD-2009-101, June 21-25, Seattle, WA.

12. Buffum, D.H., "Blade Row Interaction Effects on Flutter and Forced Response," AIAA Paper 932084, 29th Joint Propulsion Conference, Monterey, CA, June 28-July 1, 1993. NASA TM-106438.

13. Hall, K.C. and Silkowski, P.D., "The Influence of Neighboring Blade Rows on the Unsteady Aerodynamic Response of Cascades," J. of Turbomachinery, 119 (1), pp. 85-93, 1997.

14. Silkowski, P.D. and Hall, K.C., "A Coupled Mode Analysis of Unsteady Multistage Flows in Turbomachinery," J. of Turbomachinery, 120 (3), pp. 410-421, 1998.

15. Hall, K.C., "Modeling of Unsteady Three-Dimensional Flows in Multistage Machines," NASA/CR2003-212101, Jan. 2003.

16. Ekici, K., Voytovych, D.M., Hall, K.C., "Time Linearized Navier-Stokes Analysis of Flutter in Multistage Turbomachines," AIAA-2005-0836, 43rd AIAA Aerospace Sciences Meeting and Exhibit, 10-13 Jan. 2005, Reno, NV.

17. Hall, K.C. and Ekici, K., "Multistage Coupling for Unsteady Flows in Turbomachinery," AIAA Journal, Vol. 43, No. 3, Mar. 2005

18. Ekici, K. and Hall, K.C., "Nonlinear Analysis of Unsteady Flows in Multistage Turbomachines Using Harmonic Balance," AIAA Journal, Vol. 45, No. 5, May 2007.

19. Strazisar, A.J., Wood, J.R., Hathaway, M.D. and Suder, K.L., "Laser Anemometer Measurements in a Transonic Axial-Flow Fan Rotor," NASA TR-2879, 1989.

20. Hathaway, M.D., "Unsteady Flows in a Single-Stage Transonic Axial-Flow Fan Stator Row," NASA TM-88929, Dec. 1986.

21. Ekici, K., Hall, K.C. and Kielb, R.E., "Harmonic Balance Analysis of Forced Response in a Transonic Compressor," AIAA-2009-1240, 47thAIAA Aerospace Sciences Meeting and Exhibit, 5-8 Jan. 2009, Orlando, FL. 


\begin{tabular}{|c|c|c|}
\hline \multicolumn{2}{|c|}{ REPORT DOCUMENTATION PAGE } & $\begin{array}{l}\text { Form Approved } \\
\text { OMB No. 0704-0188 }\end{array}$ \\
\hline \multicolumn{3}{|c|}{ 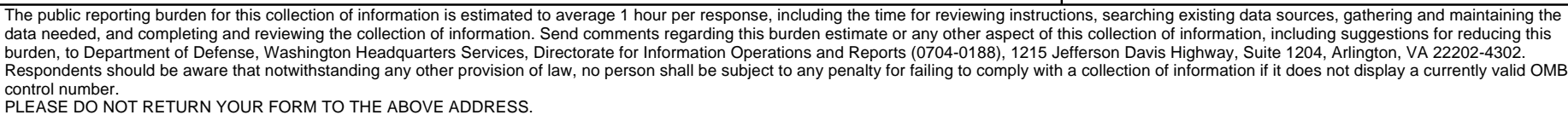 } \\
\hline $\begin{array}{l}\text { 1. REPORT DATE (DD-MM-YYYY) } \\
01-07-2010\end{array}$ & $\begin{array}{l}\text { 2. REPORT TYPE } \\
\text { Technical Memorandum }\end{array}$ & 3. DATES COVERED (From - To) \\
\hline \multirow{3}{*}{\multicolumn{2}{|c|}{$\begin{array}{l}\text { 4. TITLE AND SUBTITLE } \\
\text { Aeroelastic Computations of a Compressor Stage Using the Harmor }\end{array}$}} & 5a. CONTRACT NUMBER \\
\hline & & 5b. GRANT NUMBER \\
\hline & & 5c. PROGRAM ELEMENT NUMBER \\
\hline \multirow{3}{*}{\multicolumn{2}{|c|}{$\begin{array}{l}\text { 6. AUTHOR(S) } \\
\text { Reddy, T., S., R.; Bakhle, Milind, A. }\end{array}$}} & 5d. PROJECT NUMBER \\
\hline & & 5e. TASK NUMBER \\
\hline & & $\begin{array}{l}\text { 5f. WORK UNIT NUMBER } \\
\text { WBS 561581.02.08.03.21.03 }\end{array}$ \\
\hline \multicolumn{2}{|c|}{$\begin{array}{l}\text { 7. PERFORMING ORGANIZATION NAME(S) AND ADDRESS(ES) } \\
\text { National Aeronautics and Space Administration } \\
\text { John H. Glenn Research Center at Lewis Field } \\
\text { Cleveland, Ohio 44135-3191 }\end{array}$} & $\begin{array}{l}\text { 8. PERFORMING ORGANIZATION } \\
\text { REPORT NUMBER } \\
\text { E-17227 }\end{array}$ \\
\hline \multirow{2}{*}{\multicolumn{2}{|c|}{$\begin{array}{l}\text { 9. SPONSORING/MONITORING AGENCY NAME(S) AND ADDRESS(ES) } \\
\text { National Aeronautics and Space Administration } \\
\text { Washington, DC 20546-0001 }\end{array}$}} & $\begin{array}{l}\text { 10. SPONSORING/MONITOR'S } \\
\text { ACRONYM(S) } \\
\text { NASA }\end{array}$ \\
\hline & & $\begin{array}{l}\text { 11. SPONSORING/MONITORING } \\
\text { REPORT NUMBER } \\
\text { NASA/TM-2010-216240 }\end{array}$ \\
\hline \multicolumn{3}{|c|}{$\begin{array}{l}\text { 12. DISTRIBUTIONIAVAILABILITY STATEMENT } \\
\text { Unclassified-Unlimited } \\
\text { Subject Category: } 39 \\
\text { Available electronically at http://gltrs.grc.nasa.gov } \\
\text { This publication is available from the NASA Center for AeroSpace Information, 443-757-5802 }\end{array}$} \\
\hline
\end{tabular}

\section{SUPPLEMENTARY NOTES}

\section{ABSTRACT}

The aeroelastic characteristics of a compressor stage were analyzed using a computational fluid dynamic (CFD) solver that uses the harmonic balance method to solve the governing equations. The three dimensional solver models the unsteady flow field due to blade vibration using the Reynolds-Averaged Navier-Stokes equations. The formulation enables the study of the effect of blade row interaction through the inclusion of coupling modes between blade rows. It also enables the study of nonlinear effects of high amplitude blade vibration by the inclusion of higher harmonics of the fundamental blade vibration frequency. In the present work, the solver is applied to study in detail the aeroelastic characteristics of a transonic compressor stage. Various parameters were included in the study: number of coupling modes, blade row axial spacing, and operating speeds. Only the first vibration mode is considered with amplitude of oscillation in the linear range. Both aeroelastic stability (flutter) of rotor blade and unsteady loading on the stator are calculated. The study showed that for the stage considered, the rotor aerodynamic damping is not influenced by the presence of the stator even when the axial spacing is reduced by nearly 25 percent. However, the study showed that blade row interaction effects become important for the unsteady loading on the stator when the axial spacing is reduced by the same amount.

15. SUBJECT TERMS

Flutter and forced response; Computational fluid dynamics; Blade row interaction; Modal formulation; Time domain; Harmonic balance

\begin{tabular}{|c|c|c|c|c|c|}
\hline \multicolumn{3}{|c|}{ 16. SECURITY CLASSIFICATION OF: } & \multirow{2}{*}{$\begin{array}{l}\text { 17. LIMITATION OF } \\
\text { ABSTRACT } \\
\text { UU }\end{array}$} & \multirow{2}{*}{$\begin{array}{l}\text { 18. NUMBER } \\
\text { OF } \\
\text { PAGES } \\
28\end{array}$} & \multirow{2}{*}{$\begin{array}{l}\text { 19a. NAME OF RESPONSIBLE PERSON } \\
\text { STI Help Desk (email:help@sti.nasa.gov) } \\
\text { 19b. TELEPHONE NUMBER (include area code) } \\
\text { 443-757-5802 }\end{array}$} \\
\hline $\begin{array}{l}\text { a. REPORT } \\
\mathrm{U}\end{array}$ & $\begin{array}{l}\text { b. ABSTRACT } \\
\mathrm{U}\end{array}$ & $\begin{array}{l}\text { c. THIS } \\
\text { PAGE } \\
\text { U }\end{array}$ & & & \\
\hline
\end{tabular}



